\title{
Sustainable Performance of a Modular Building System Made of Built-Up Cold-Formed Steel Beams
}

\author{
Kajaharan Thirunavukkarasu ${ }^{1}$, Elilarasi Kanthasamy ${ }^{2}$, Perampalam Gatheeshgar ${ }^{2}$, Keerthan Poologanathan ${ }^{2, *} *$, \\ Heshachanaa Rajanayagam ${ }^{2}$, Thadshajini Suntharalingam ${ }^{2}$ and Madhushan Dissanayake ${ }^{2}$ \\ 1 Institute of Technology, University of Moratuwa, Homagama 10200, Sri Lanka; kajaharan28@gmail.com \\ 2 Faculty of Engineering and Environment, University of Northumbria, Newcastle upon Tyne NE1 8ST, UK; \\ elilarasi.kanthasamy@northumbria.ac.uk (E.K.); g.perampalam@northumbria.ac.uk (P.G.); \\ heshacana.rajanagam@northumbria.ac.uk (H.R.); thadshayini.sunthalingam@northumbria.ac.uk (T.S.); \\ madhusan.mudiyanselge@northumbria.ac.uk (M.D.) \\ * Correspondence: keerthan.poologanathan@northumbria.ac.uk
}

\section{check for}

updates

Citation: Thirunavukkarasu, K.; Kanthasamy, E.; Gatheeshgar, P.; Poologanathan, K.; Rajanayagam, H.; Suntharalingam, T.; Dissanayake, $\mathrm{M}$. Sustainable Performance of a Modular Building System Made of Built-Up Cold-Formed Steel Beams. Buildings 2021, 11, 460. https:// doi.org/10.3390/buildings11100460

Academic Editor: Francisco

López Almansa

Received: 18 July 2021

Accepted: 25 September 2021

Published: 8 October 2021

Publisher's Note: MDPI stays neutra with regard to jurisdictional claims in published maps and institutional affiliations.

Copyright: (c) 2021 by the authors. Licensee MDPI, Basel, Switzerland. This article is an open access article distributed under the terms and conditions of the Creative Commons Attribution (CC BY) license (https:// creativecommons.org/licenses/by/ $4.0 /)$.

\begin{abstract}
Modular Building Systems (MBS) offer numerous benefits in terms of productivity, sustainability and safety. Therefore, MBSs are considered as a viable option to sort out the housing crisis in Britain as well as to drive Britain towards sustainable construction. Development in materials, manufacturing techniques, connection types and structural designs with respect to offsite construction is essential to achieve sustainable goals. Recent advancements in steel manufacturing, including ColdFormed Steel (CFS), have showed potential benefits in structural performance compared to concrete and timber. Meanwhile, research was conducted to enhance the structural capacities of CFS sections by introducing different cross-sections, composite sections and techniques including optimization. Built-up sections were developed by connecting more than one channel section, and various research studies were conducted to assess their structural performances. However, sustainable performance of built-up sections in modular constructions is still unknown. Hence, this paper intends to develop an MBS using built-up sections for better sustainable performance. Literature review was carried out on the sustainability benefits of MBSs in terms of economic, environmental and social aspects. In addition to that, numerical analysis was performed to investigate the flexural capacity of built-up sections with different screw arrangements to address the sustainable aspects of modular construction by introducing novel sections. The numerical description, results and validations are also stated. Numerical results revealed that flexural capacities of built-up sections are improved up to $156 \%$ than those of single sections. Finally, the utilization of built-up sections in modular construction with sustainability enhancement is addressed and illustrated in a conceptual diagram.
\end{abstract}

Keywords: modern methods of construction; modular building system; cold-formed steel; sustainability; built-up sections; numerical analysis

\section{Introduction}

Every now and then, several ancient industries such as manufacturing, textile, food and agriculture have evolved by adapting new technologies. However, the construction industry remained stubborn in the adoption of new technologies, excluding of machineries, which were introduced to reduce human effort and time. Conventional methods of construction are labour intensive, time consuming, less productive, less predictable, high energy consuming (buildings account for $32 \%$ of global energy and almost $10 \%$ of energy related to direct $\mathrm{CO}_{2}$ emissions [1]), threatening to the environment in terms of carbon emissions (the building sector is responsible for $40 \%$ of global carbon emission [2]), air pollution and noise pollution and subjected to weather constraints, but are still considered as the predominant construction practice even in developed countries such as the United Kingdom (UK), Australia and the United States of America (USA). However, countries 
including Sweden, Norway, Finland, the Netherlands and Japan have moved on to sustainable modern construction methods by replacing 70-95\% [3] of site works with offsite modular construction, which is one of the highly rated Modern Methods of Construction (MMC). Current modular housing percentages in developed countries are stated in Table 1.

Table 1. Percentage of modular housing in developed countries [4-6].

\begin{tabular}{ccccccccc}
\hline Country & UK & USA & Australia & China & Germany & Japan & Sweden \\
\hline$\%$ of modular housing & $5-7$ & $3-5$ & 5 & 6 & $9-10$ & 15 & $40-80$ \\
\hline
\end{tabular}

Modular construction replicates the manufacturing industry in terms of production procedures, such as module or unit fabrication and assembling the modules to achieve the ultimate output. The word offsite indicates that the majority of construction work, which is module fabrication, is carried out in factories rather than construction sites. Figure 1 shows modular fabrication in factories. Modular construction has numerous benefits including enhancement of quality [7], faster delivery [8] (20-70\% faster than traditional method [9]), reduction in costs $(20 \%[4,10])$, efficient material usage, being environmentally friendly in terms of less energy consumption, reduced greenhouse gas emissions, a reduction in noise pollution (30-50\%) [11] and efficient water usage, reduced labour demand, a reduction in construction wastage (up to 90\% [12]), improved health and safety aspects (fall in accident rate by $80 \%$ [11]), reduced traffic movements ( $70 \%$ less than traditional methods [13]) related to construction and improved aesthetic options in the buildings. Faster delivery of buildings, especially hospitals, hostels and office buildings, is the most impressive benefit of modular constructions considering the increase in population. For example, China was able to complete a 1000-bed hospital within 14 days using the modular construction concept to address the COVID-19 treatment and hospitalization issues as the number of patients kept increasing [2]. The timeline comparison of modular and traditional construction for a typical building is illustrated in Figure 2 .

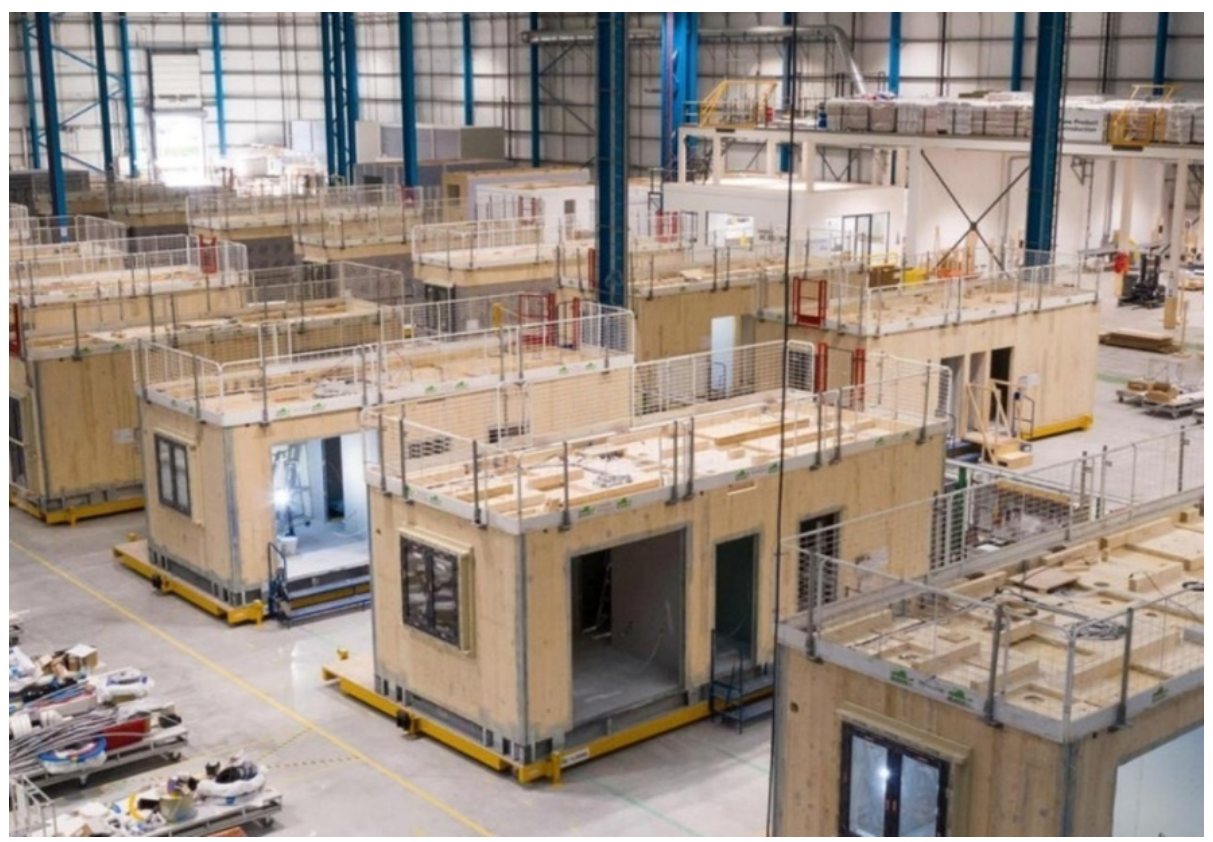

Figure 1. Prefabricated modules in a factory [14].

On the occasions where the traditional construction methods were not able to accomplish the demand, especially in the housing sector, the non-traditional methods were developed. After World War I and II, a huge housing crisis and shortage of labour and materials led to innovative non-traditional methods, which were the origin of the Modular 
Building System (MBS) concept $[4,15,16]$. Figure 3 shows the prefabricated volumetric module showcased in an exhibition in London, 1945 [16]. Focus on industrial redevelopment and a boom in high rise buildings around the 1960s led to the re-emergence of non-traditional methods of construction. Over 425,000 houses were built in the UK in 1968 utilizing offsite techniques [17], which is much greater than recent years' annual demand $(300,000)[18]$ in the UK. Over the years, innovation in the construction industry was limited to a much lower percentage compared to the traditional methods considering several barriers, including high capital costs [19], lack of suppliers, lack of flexibility in site, misperceptions and lack of experience to adapt [9]. House building sector statistics in the last 40 years illustrate the adverse effects of traditional methods in productivity as a continuous decline in the completion of houses in the UK was observed [5]. However, sustainability, a housing shortage and productivity concerns in the construction industry in recent years have set up an ideal platform to enhance the utilization of MMC [4]. The UK government initiated sustainable development progress in 2003 by forming a task group to ensure environmental protection, effective usage of materials and stability of economic growth and employment [20]. Figure 4 illustrates the phases of an emerging technology. With regard to the Gartner hype cycle, modular construction is now moving forward to a plateau of productivity from the slope of the enlightenment phase.

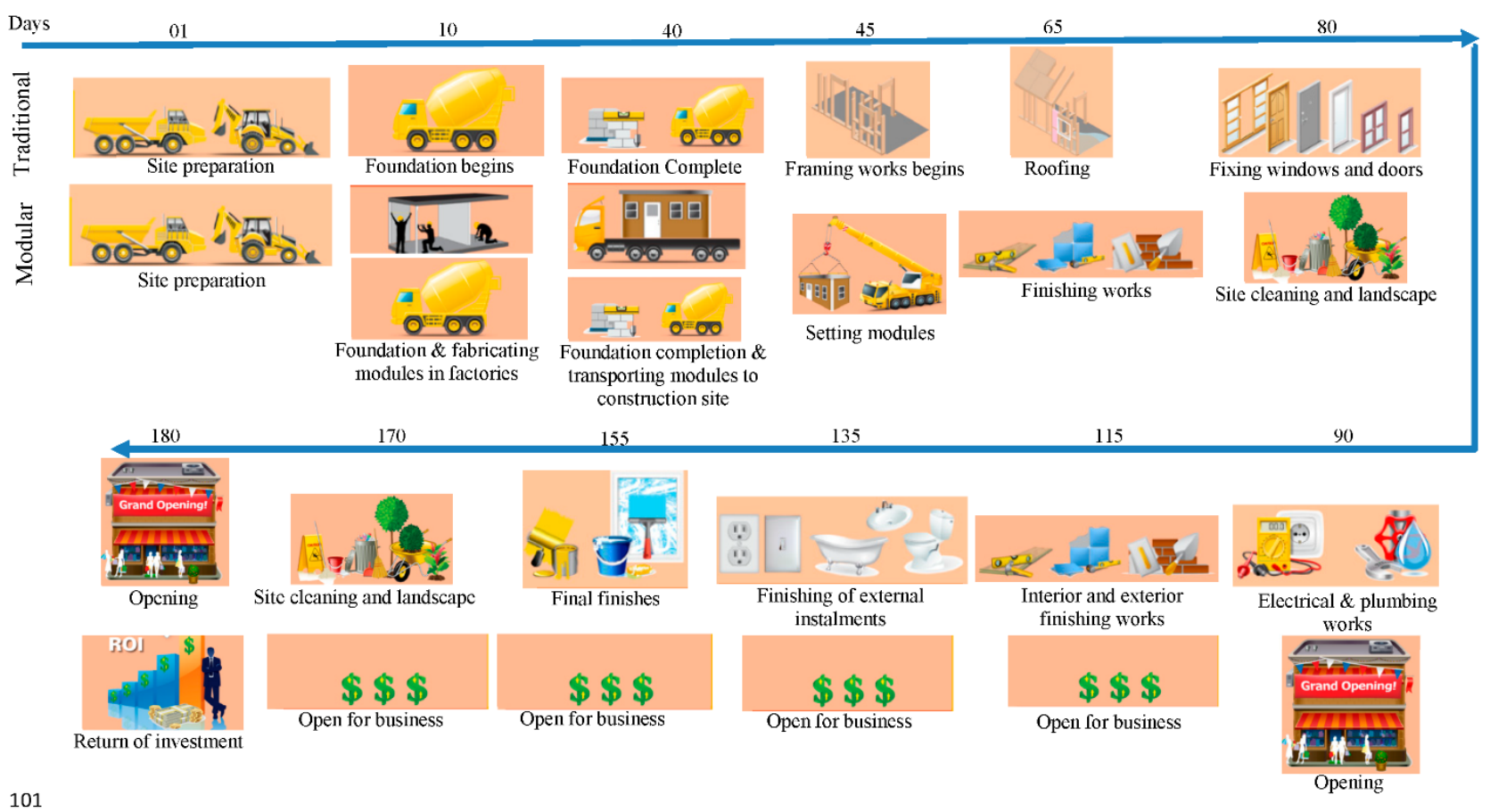

Figure 2. Comparison of modular construction and conventional construction [21]. 


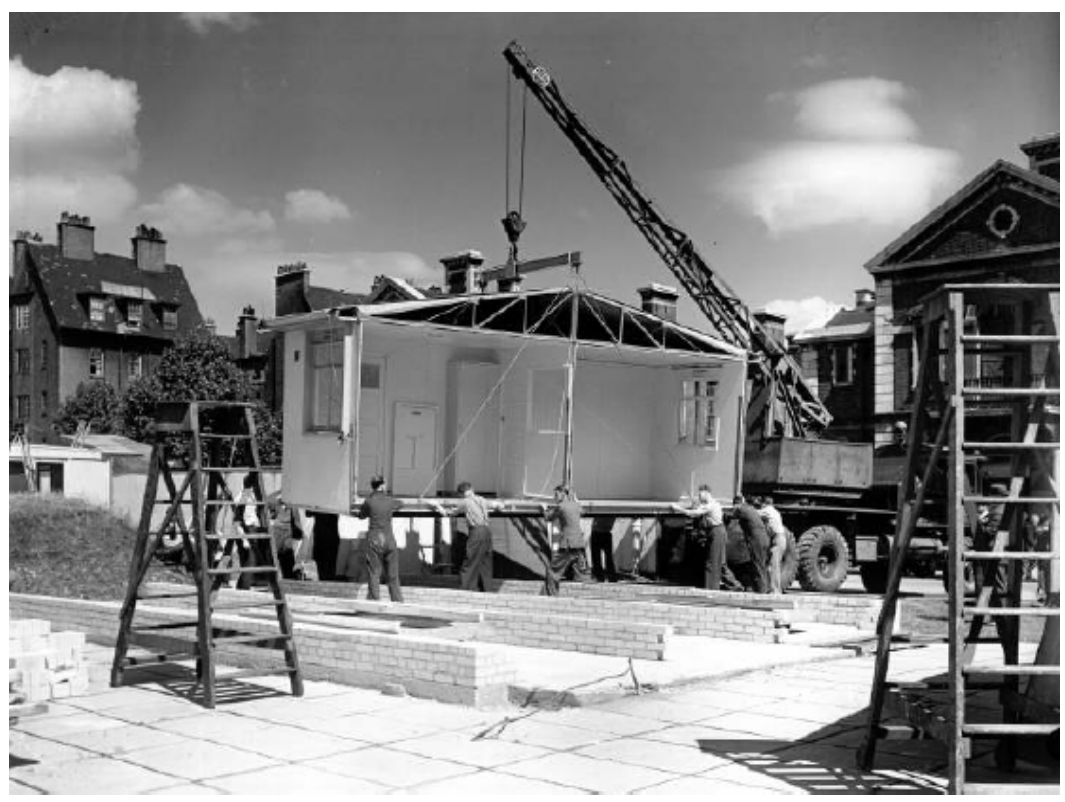

Figure 3. Prefabricated volumetric module at London Exhibition, 1945 [16].

Farmer reviews on the labour model of the construction industry in the UK have changed the views of the government towards the construction industry. Since it is indicated that the continuous labour shortage and lack of investment in the skills development of labourers are going to be crucial issues in the future, the main concept, "modernise or die", was considered as a wakeup call to the construction industry [22]. It was well received by the UK government and they responded with plans to improve housing supply through the MMC [23]. Figure 5 indicates the labour capacity and forecast in the UK. Moreover, recent industry reports [24], government reports [25], strategic plans [26] and research studies [2] are pointing out the sustainable benefits of the MMC, which will be profitable in achieving sustainable targets [27] set by the government and the United Nations (UN) [28]. In particular, Construction 2025, the strategy plan of the UK, aims at a $33 \%$ reduction in initial and lifetime costs, 50\% faster construction, $50 \%$ lower emissions and 50\% improvement in exports by 2025. However, the recent COVID-19 pandemic situation slowed down the progress [29] of the construction productivity rate (25\% drop in construction activities [30]), and annual targets were not achieved according to the road map plan. Moreover, in the post-Brexit period, the construction industry is facing huge issues such as labour shortage, high material costs and funding shortages [6]. A recovery plan [30] (restart, reset and reinvent) is in progress to achieve the targets in terms of housing demand and sustainability, and modular construction is highlighted as the main theme in the recovery plan considering the new norms in regard to the pandemic, such as social distancing and less crowding. 


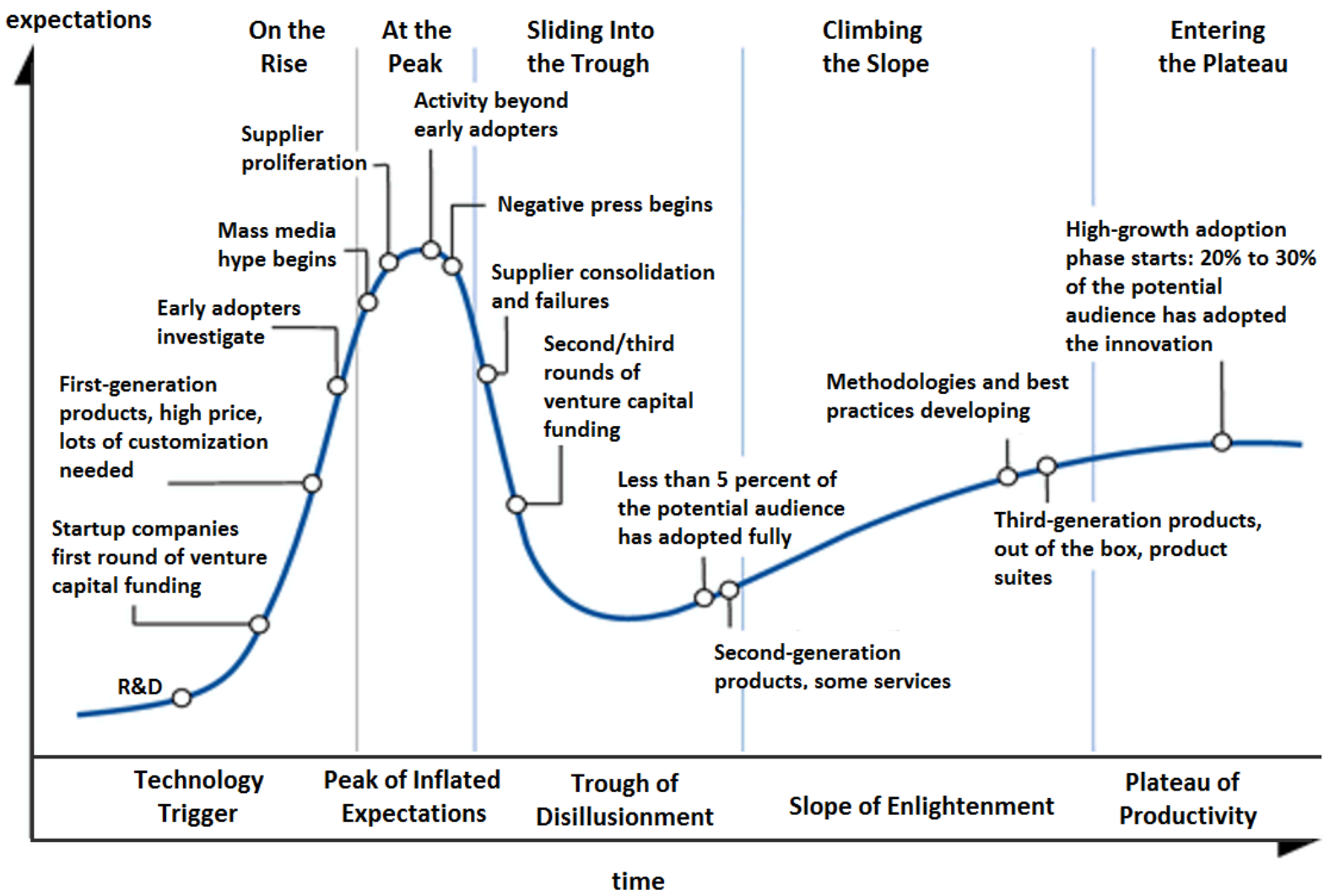

Figure 4. Gartner Hyper cycle; technology's journey to mainstream acceptance [31].

Even though modular construction is the most desirable option to achieve the ultimate goals, there are a few concerns to overcome and a huge space to experiment and propose various aspects, such as materials, techniques, connections and design guidelines [3], for an improved utilization of modular construction in the future. In particular, research studies have focused on the structural performance of modules to achieve high standards along with sustainable benefits including cost effectiveness and less consumption of raw materials [19]. The MBS depends on concrete, timber and steel for the production of modular types [32], including Light Gauge Steel Frames (LGSF), pods, precast concrete, panelised system and volumetric construction $[5,17]$. Each material has its own benefits and is used in appropriate modular constructions to meet specific needs. Steel is the highestrated and standout material for MMC considering its advantages such as reusability (more than $90-98 \%$ of steel is reused or recycled in the UK [13]), faster erection, quality control, cost benefits $(6 \%$ more cost effective compared to concrete for a six-storey apartment in an urban location [33]), less material consumption (up to 78\% compared to conventional concrete [34]) and portability (20\% lighter than concrete modules [3]). Cold-Formed Steel (CFS) is highly preferred in modular buildings as a portal steel frame system and load-bearing elements over hot-rolled steel to enhance the benefits of steel usage, specifically due to a high strength to weight ratio, structurally efficient cross-sections, material efficiency and a light weight [35]. Research was carried out on CFS sections to investigate their structural performance under various criteria such as shear, bending and web crippling [36-44]. Based on the research, new design methodologies, design equations and new cross sections were proposed. Moreover, advances in technology and visions towards sustainability [1] generated innovative ideas in the CFS industry to explore more structurally efficient crosssection shapes through optimization (search for a structural design that is optimal for a certain design criterion while satisfying other constraints), composite sections, built-up sections and innovative connections with high strength and stiffness, which are indicated as exemplary improved performances. Therefore, the application of such innovative sections and methodologies in modular constructions to achieve more sustainable benefits was 
taken into consideration by researchers. However, limited research has been carried out in this area [36-44]. Satheeskumar et al. [45] investigated sustainable benefits of a crosslaminated timber-CFS composite beam, and Gatheeshgar et al. [46] studied the role of an optimised CFS beam in modular constructions. A cross-laminated timber-CFS composite beam has enhanced flexural capacity by $20 \%$ compared to the individual capacities of both members [45], whereas optimised CFS sections such as Lipped Channel Beam (LCB), folded flange sections and super sigma sections have increased moment capacity by $30 \%$, $60 \%$ and $65 \%$, respectively [46]. Moreover, Gatheeshgar et al. [35] investigated the effect of optimisation in the shear and web crippling capacities of LCB sections. Optimization enhanced both shear and web crippling capacity by $6 \%$ and $13 \%$, respectively. Meanwhile, combined optimisation influenced the increase in flexural capacity by $12 \%$ without affecting shear and web crippling capacities. The weight optimisation method to CFS joists generated a $24 \%$ reduction in weight [2], which is ideal for modular construction considering transport and lifting processes.

Moreover, longer spans were expected in the modular building industry to increase the space within the building (client's expectation), improve the indoor aesthetic environment and reduce the material utilization (sustainability). Therefore, built-up sections were introduced to achieve industrialized production by combining two sections' webs as backto-back form or combining flanges to form as a box section. Figure 6 shows innovative built-up sections made of combining two channel sections together with self-tapping screws [47]. Built-up sections ensure more torsional stiffness due to its biaxial symmetrical nature, higher load-bearing capacity, increased spanning distance and more convenient connections [48], which are ideal features for utilization as joists in modular constructions with respect to sustainability targets.

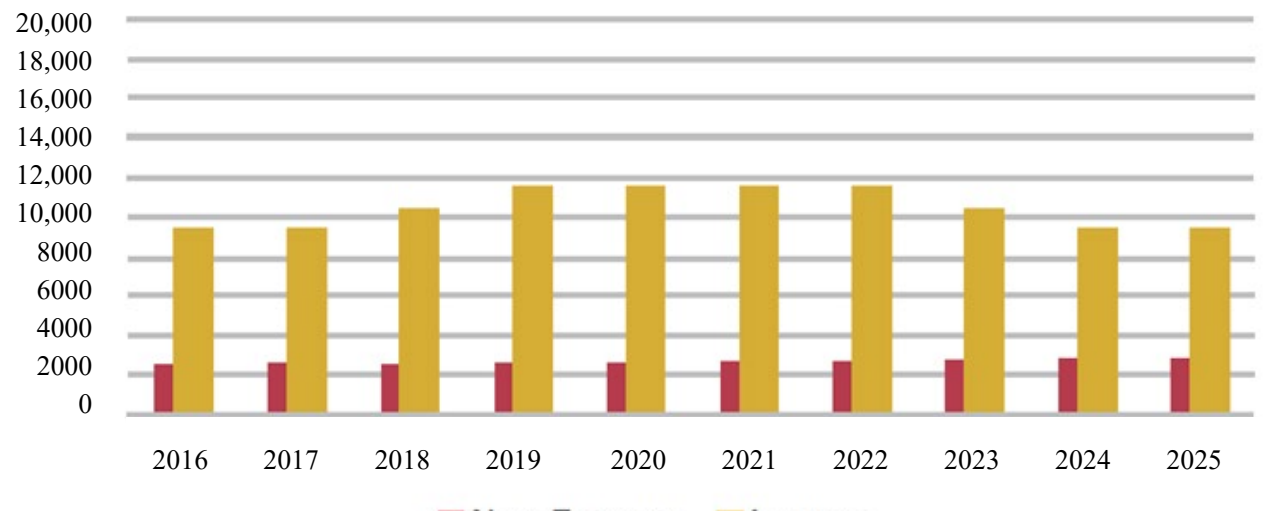

New Entrants Leavers

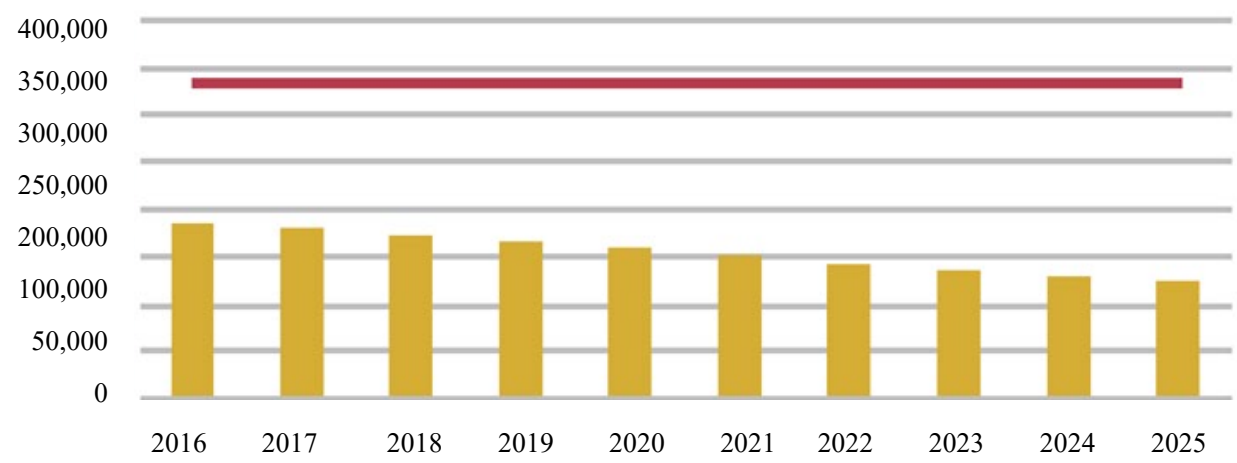

Estimate Number of Workers in Housebuilding Required Workforce to deliver 250,000 homes

Figure 5. Comparison of new entrants and leavers with available and required workforce in construction industry, UK [49]. 
Influence of self-tapping screw arrangement in the flexural performance of closed and open built-up sections was investigated by Wang and Young [47]. Screw arrangement played a significant role in the flexural capacity of closed built-up sections, whereas open section capacity was not considerably affected by the screw arrangement. However, the flexural performance of built-up sections and the influence of screw arrangement in the flexural capacity of built-up sections in modular construction with respect to sustainable aspects is yet to be analysed. Therefore, this paper aims to state an overview of modular construction, categories of modular construction and its specifications, the flexural performance of innovative built-up sections and the influence of the structural alignment of screws on the flexural capacity of built-up sections, in terms of modular construction needs, to achieve sustainable goals. Finally, a conceptual design of modular units employing the innovative built-up sections is proposed for improved sustainability.
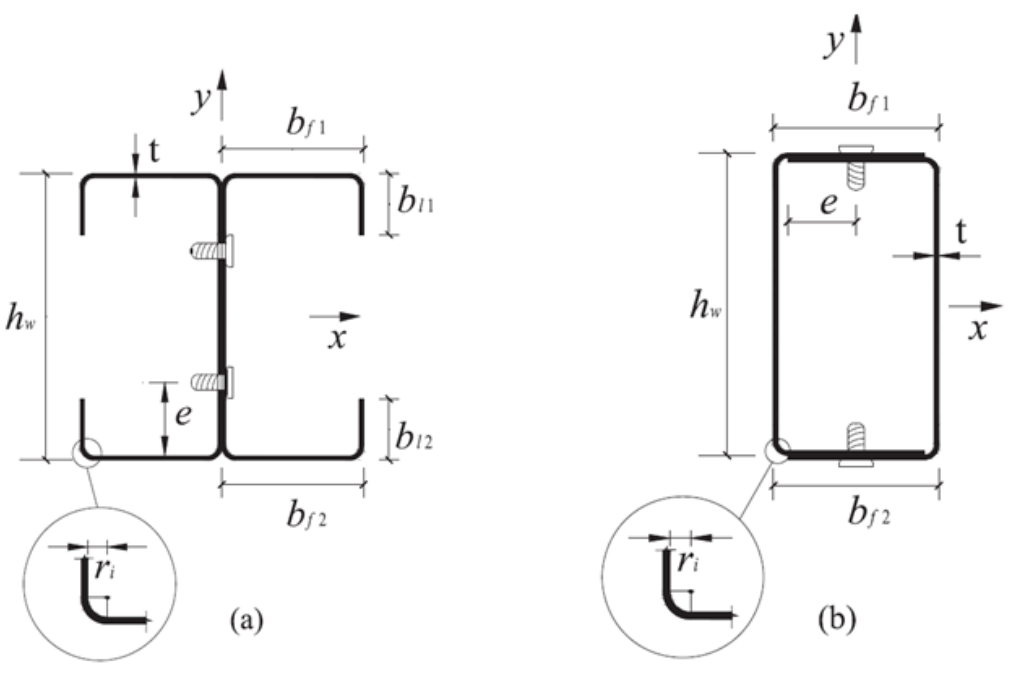

Figure 6. Built-up sections (a) open built-up section, (b) closed built-up section [47].

\section{Overview of Modular Construction}

Modular construction is defined as the onsite assembly of factory-made pre-engineered building units that could be a substantial small part or a volumetric unit with plumbing, electrical and mechanical services installed. Modular construction is often used in high rise buildings, where it has three different construction approaches, such as core, podium and in-filled frame [50]. The first two methods depend on load-bearing modules to resist vertical loads and lateral stability against wind and seismic actions and are provided by core (precast concrete or steel-concrete composite wall) and podium structures (concrete or steel or hybrid steel-concrete structures act as a foundation), respectively [3]. Therefore, both methods set the path to high-rise modular buildings with enhanced lateral stability. Figure 7 illustrates recent high-rise modular structures built all over the world using both methods [46]. Panel-based modules used in the in-filled frame method instead of traditional block or brick walls to eliminate various disadvantages including wastage, issues of being weatherproof and high cost. Lateral stability of in-filled frame structures is ensured by the traditional primary structure.

Design for Manufacture and Assembly (DfMA), a well-known method that is used to enhance quality and to improve the consistency of outputs in the automotive and consumer products sector, plays major role in multiplying the benefits of offsite constructions. Application of DfMA in modular constructions ensured a "70:60:30" pattern which denotes that $70 \%$ of offsite works in a project using DfMA guaranteed a $60 \%$ improvement in productivity and a 30\% advancement in delivery schedule [18]. DfMA aims at uncomplicated manufacturing techniques and better assembly options to achieve sustainable targets such as zero accidents and zero carbon emissions [51], which heavily depend on types of modules and materials. Module categorization and materials or components used in 
modular construction and features of each type are illustrated in Table 2, and steel modules and their features are stated in Table 3, respectively.

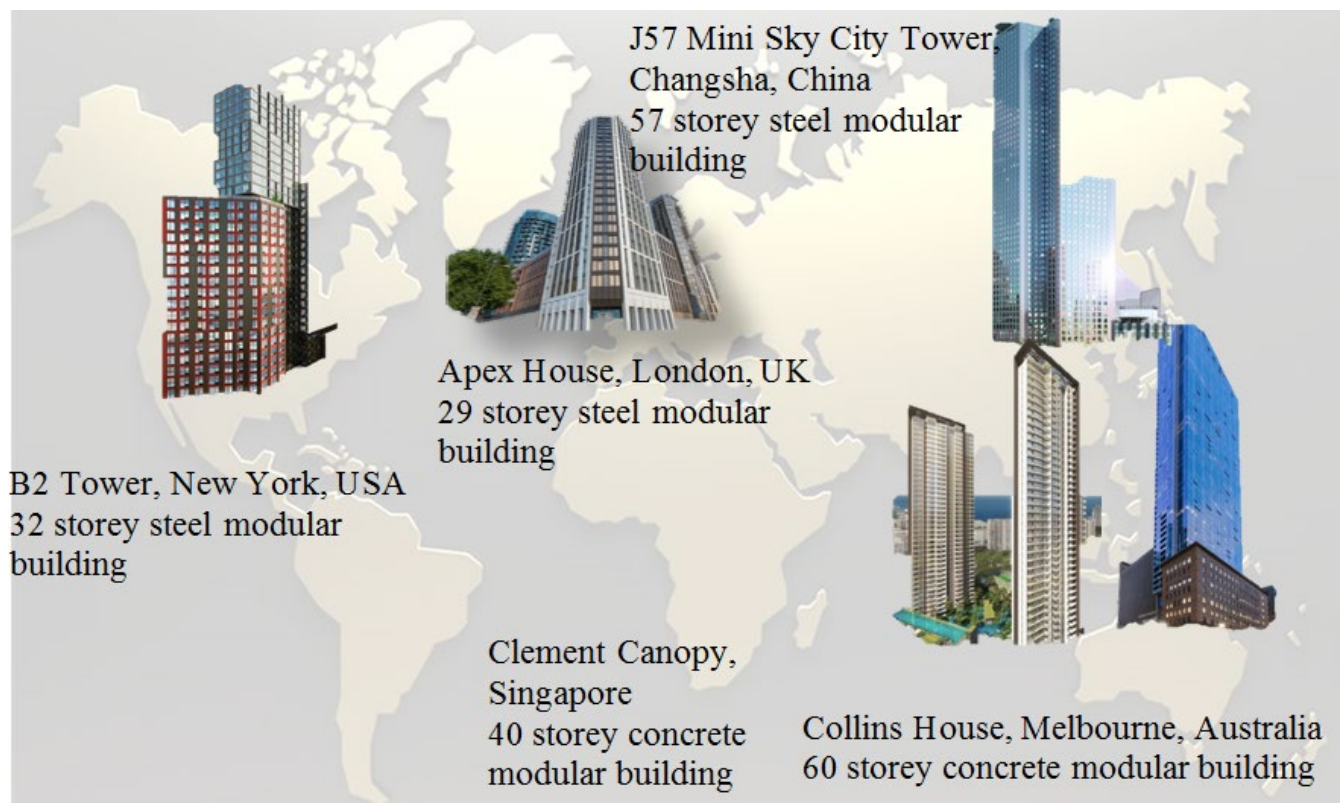

Figure 7. High-rise modular buildings [46].

Table 2. Types of modules [9,29].

Types

Volumetric type
Three-dimensional unit

- $\quad$ Fittings and finishes such as electrical, plumbing and mechanical.

- $\quad$ Either concrete or steel for high-rise buildings

- Size limitation due to transport and lifting considerations

\section{Illustration}

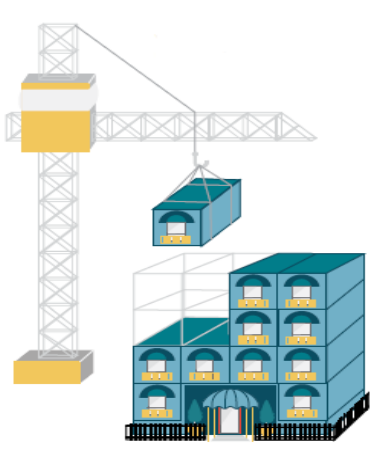

- Non-load-bearing unit

- $\quad$ Fittings and finishes

Pods

- Generally steel frame or composite

- Applications such as kitchens, office washrooms, computer show rooms and utility cupboards

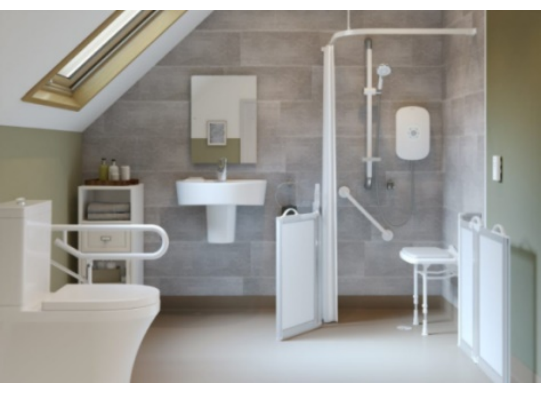


Table 2. Cont.

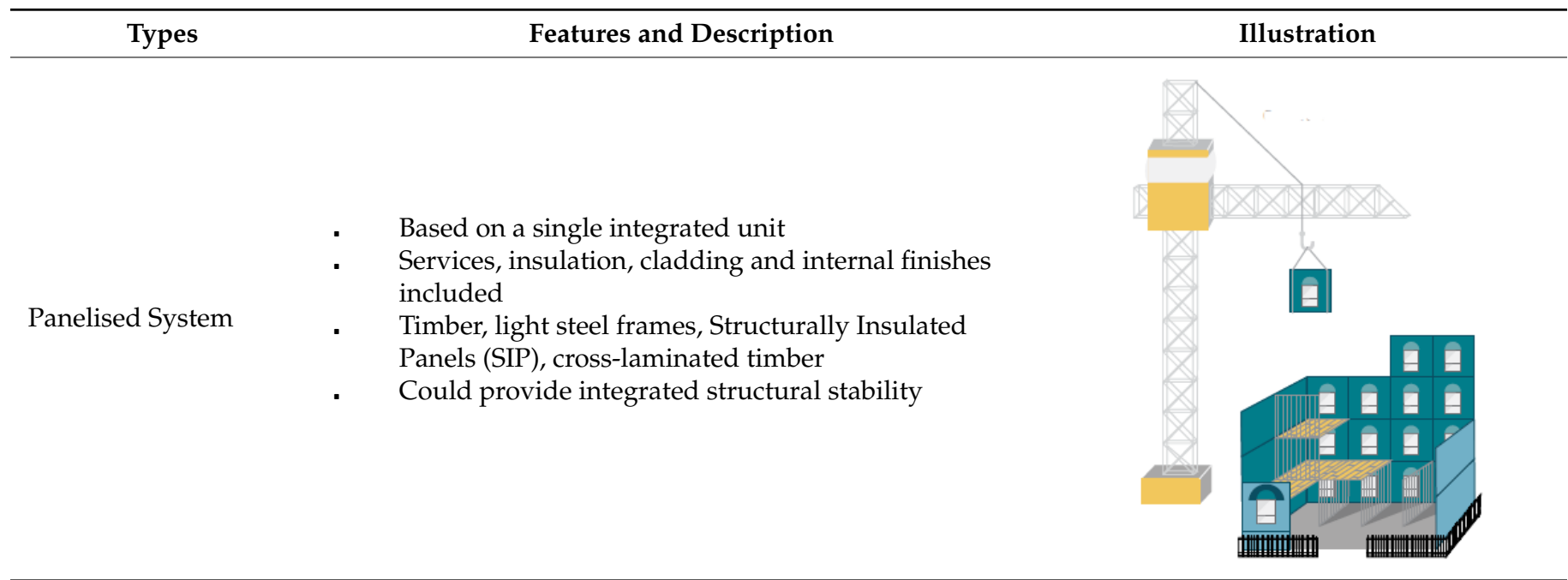

Sub-assemblies and components
- Roof and floor cassettes, prefabricated chimneys, porches and dormers, I beam

- $\quad$ Factory-made large components, but not a primary structure

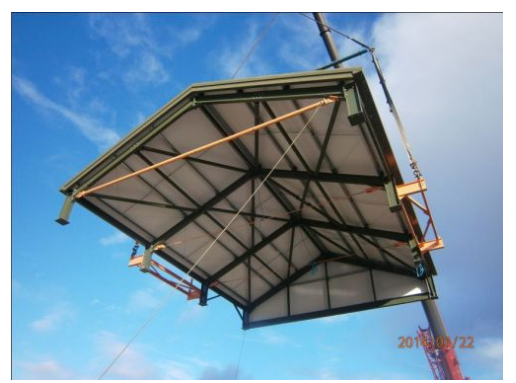

Table 3. Types of steel modules used in modular construction [17].

\begin{tabular}{|c|c|c|}
\hline Types & Characteristics & Illustration \\
\hline $\begin{array}{l}\text { Four-sided } \\
\text { modules }\end{array}$ & $\begin{array}{l}\text { - } \quad \text { Transfer loads through longitudinal walls } \\
\text { Used in cellular buildings such as hotels, hostels } \\
\text { and worker accommodation } \\
\text { Additional steel angle members used to improve } \\
\text { stability }\end{array}$ & \\
\hline $\begin{array}{l}\text { Partially open } \\
\text { side modules }\end{array}$ & $\begin{array}{l}\text { - Introduction of corner and intermediate posts } \\
\text { Bending resistance influences the maximum width } \\
\text { of the openings } \\
\text { - Temporary restraints needed to improve stability } \\
\text { - } \quad \text { Used in communal area, apartments, hotel rooms } \\
\text { with corridor }\end{array}$ & \\
\hline
\end{tabular}


Table 3. Cont.

\begin{tabular}{lll}
\hline \multicolumn{1}{c}{ Types } & \multicolumn{1}{c}{ Characteristics } \\
\hline $\begin{array}{l}\text { Fully open side, load transfer through corner posts } \\
\text { Corner } \\
\text { Mopported }\end{array}$ & - $\begin{array}{l}\text { Hot Rolled Steel members used in framework } \\
\text { improve the stability }\end{array}$ &
\end{tabular}

The performance of modular construction depends on the strength of each module as well as the connection types that are used to connect modules, as shear, bending moments, lateral loads, and vertical loads are transferred through these connections. Connections play significant roles in maintaining the stability, robustness, safety and integrity of the modular structures. Compared to traditional construction, modular constructions have many connections as all of the individual modules should be connected to build the ultimate structure. Moreover, connections should be designed considering their deformation capacity, strength and stiffness [52]. However, cost and work schedule aspects should be taken into account in the design phase as the number of connections directly influences the budget and schedule of a project. MBS connections are categorized as intra-module, inter-module and module to foundation connections. Figure 8 shows the connection types and their attributes.

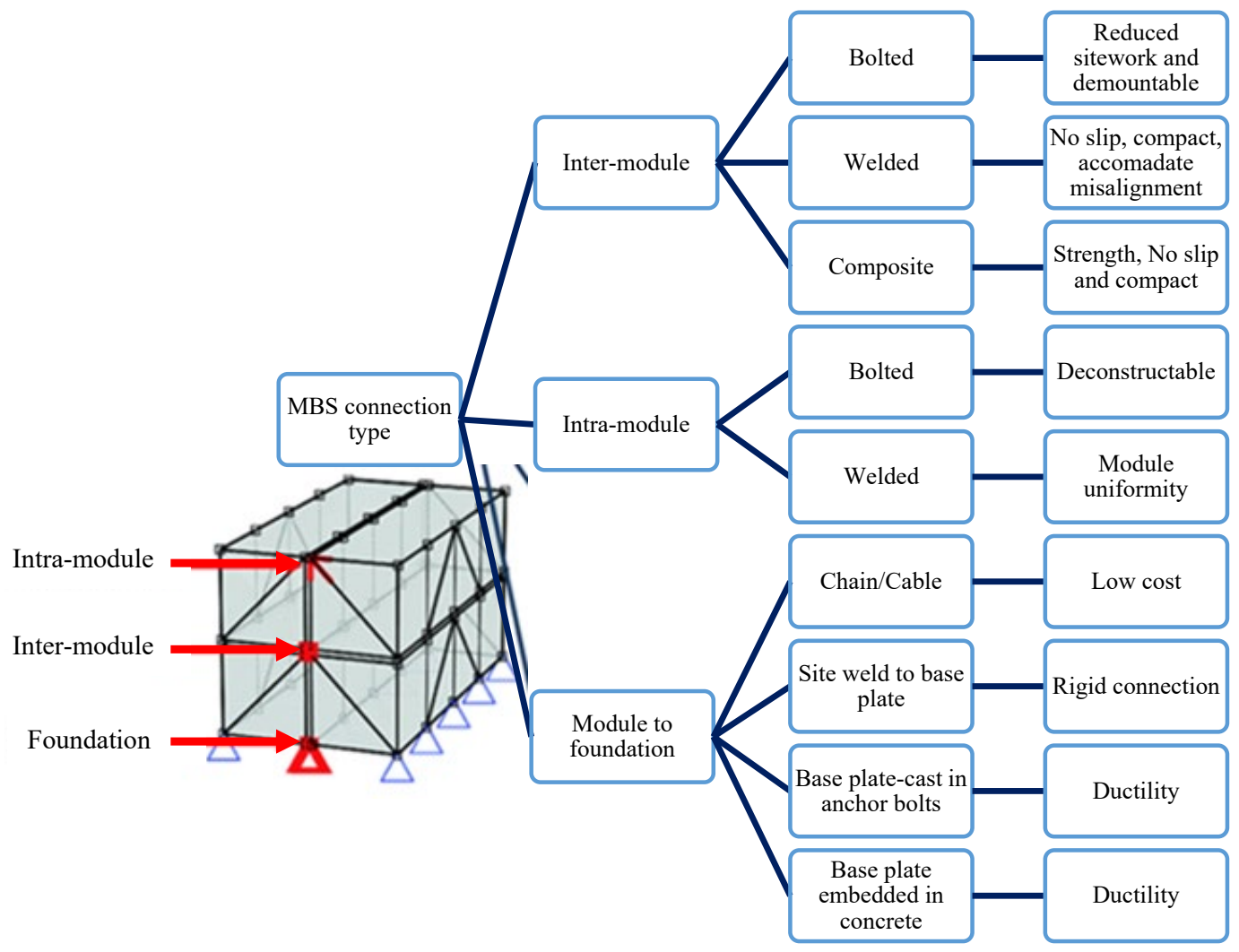

Figure 8. Modular connection types [53]. 
Innovative connection systems such as the VectorBloc connection system [54], Bolted Endplate connection system [55], vertical post-tensioned connection [56] and steel bracket connections [57] were introduced to the MBS to enhance the effectiveness of connections. However, further developments through research into sustainability aspects are needed to improve the stability of modular structures, especially high-rise modular structures.

Structural performance enhancement in modular constructions is in progress by introducing innovative materials and cross sections, strengthened connections and new design methodologies. However, performance of modular buildings in terms of fire resistance is also equally significant. Since MMC mainly depends on CFS sections and other metal sections, modular constructions are prone to fire accidents. Figure 9 shows the disastrous effects of the Grenfell Tower fire accident, which happened in June 2017, which was one of the UK's worst disasters. After such fire accidents, concerns about the fire resistance period of a building were increased. The minimum period of fire resistance with a sprinkler system for different types of buildings in the UK is indicated in Figure 10.
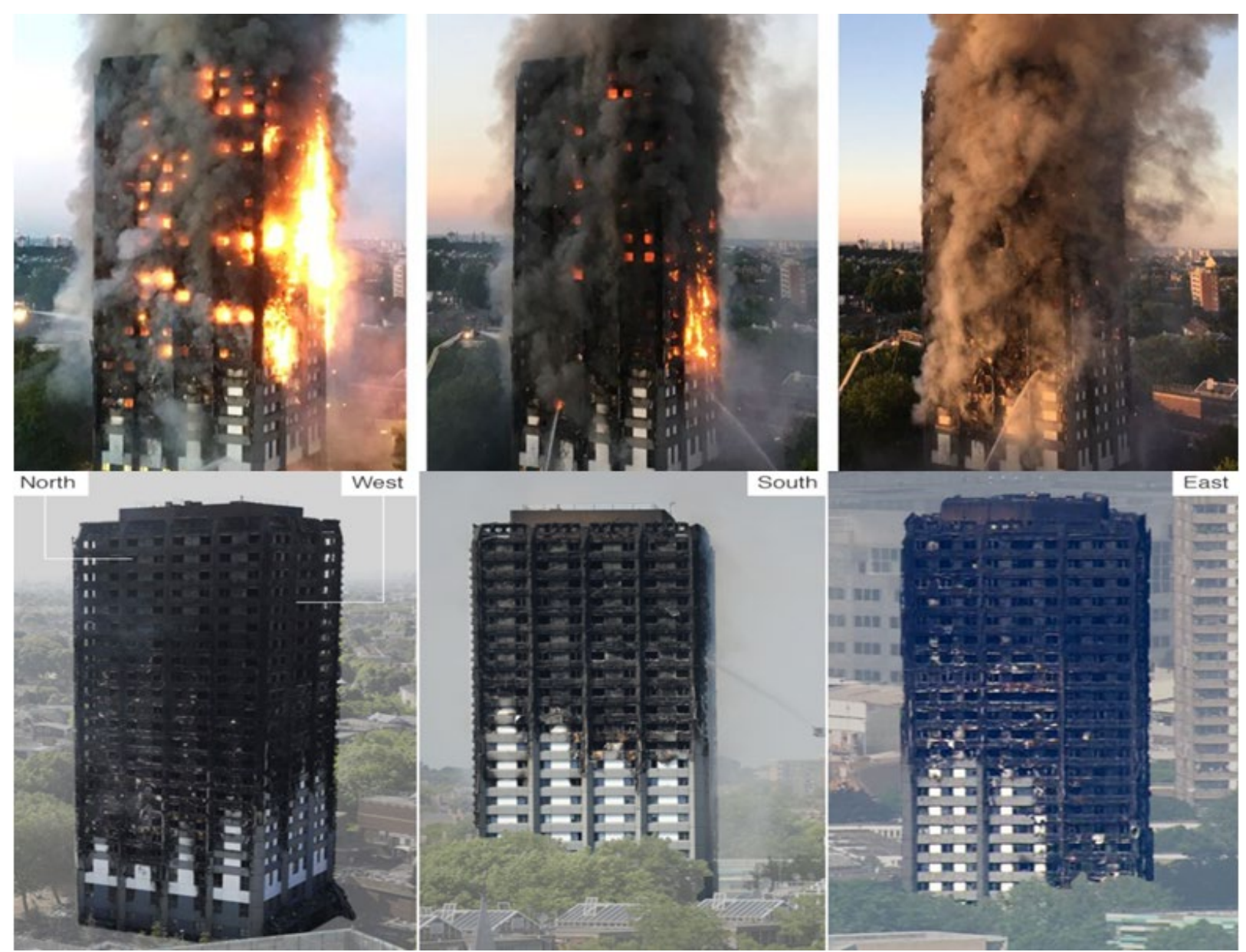

Figure 9. Fire accident in Grenfell Tower, UK [58]. 


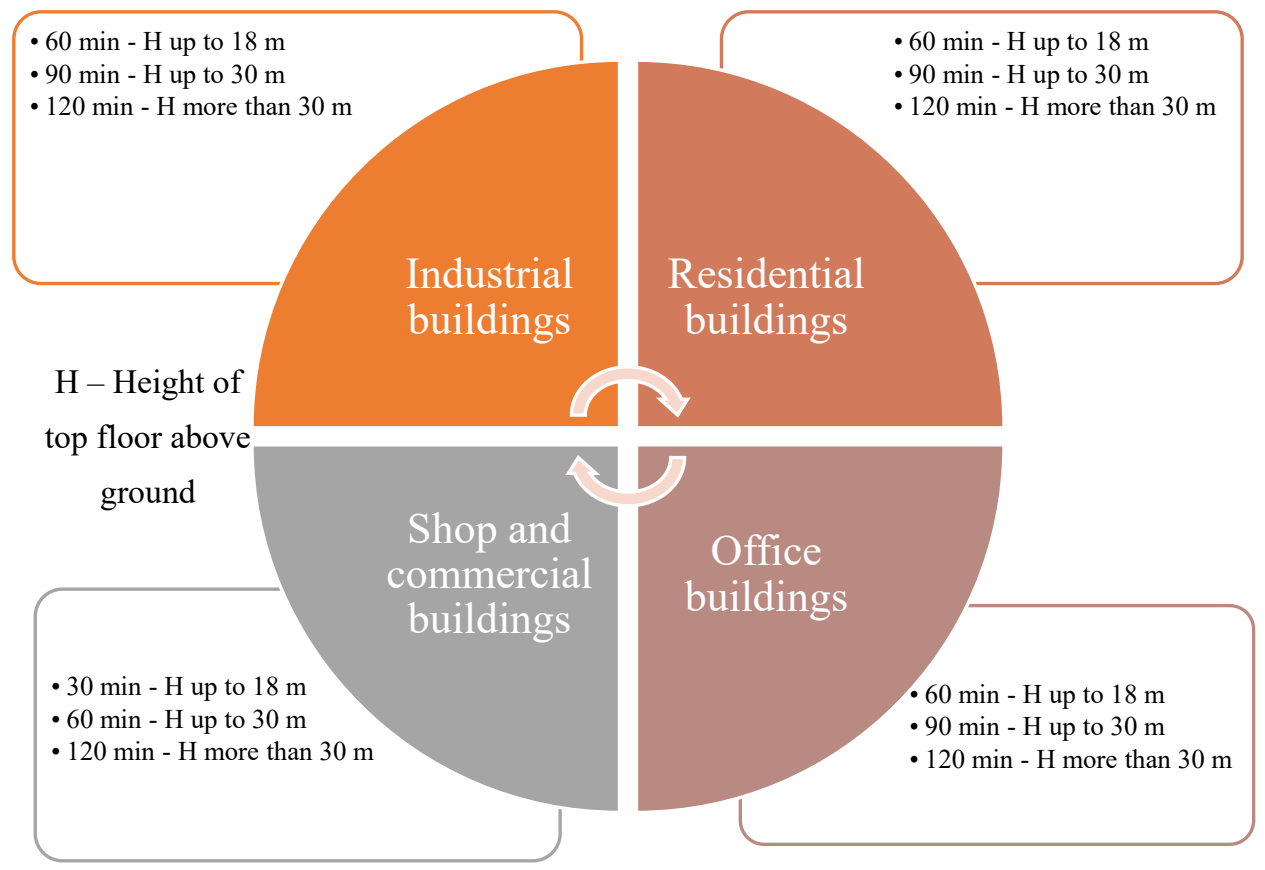

Figure 10. Minimum fire resistance period [59].

MBS has to provide sufficient fire resistance, which depends on the performance of four aspects of modular constructions, such as fire barriers between two modules to prevent fire and smoke through cavities of modules, double leaf in the wall and ceiling in limiting heat transfer, the floor load capacity, which is influenced by the thermal shielding effect of beneath the ceiling module, and the stability of the wall, which depends on the load applied and the fire protection of the internal surface. Plaster boards consisting of vermiculite or glass fibre are used in-between floors and walls, whereas mineral wool is used in-between $\mathrm{C}$ sections to achieve required fire resistance $(120 \mathrm{~min})$ [60]. Figure 11 indicates the fire insulation for a light steel framing. However, novel ideas including optimised sections [61], Fibre Reinforced Concrete (FRC) [62] and staggered slotted perforated CFS channels [2] were introduced to enhance the fire protection of modular buildings, and research is ongoing for further improvisation.

In recent times, innovations in modular buildings in terms of material usage, reducing modular unit weights, increased modular spans and joining techniques for fast installation are inevitable. Moreover, all of these innovations are going to be a stepping stone to achieve the sustainable goals. However, there is huge space to explore as the sustainable goals related to constructions appear too far away since the pandemic pushed the target further than before. Nevertheless, modular buildings will have a huge role to play in achieving sustainability benefits, and the sustainability benefits of modular building will be discussed further in contiguous sections. 


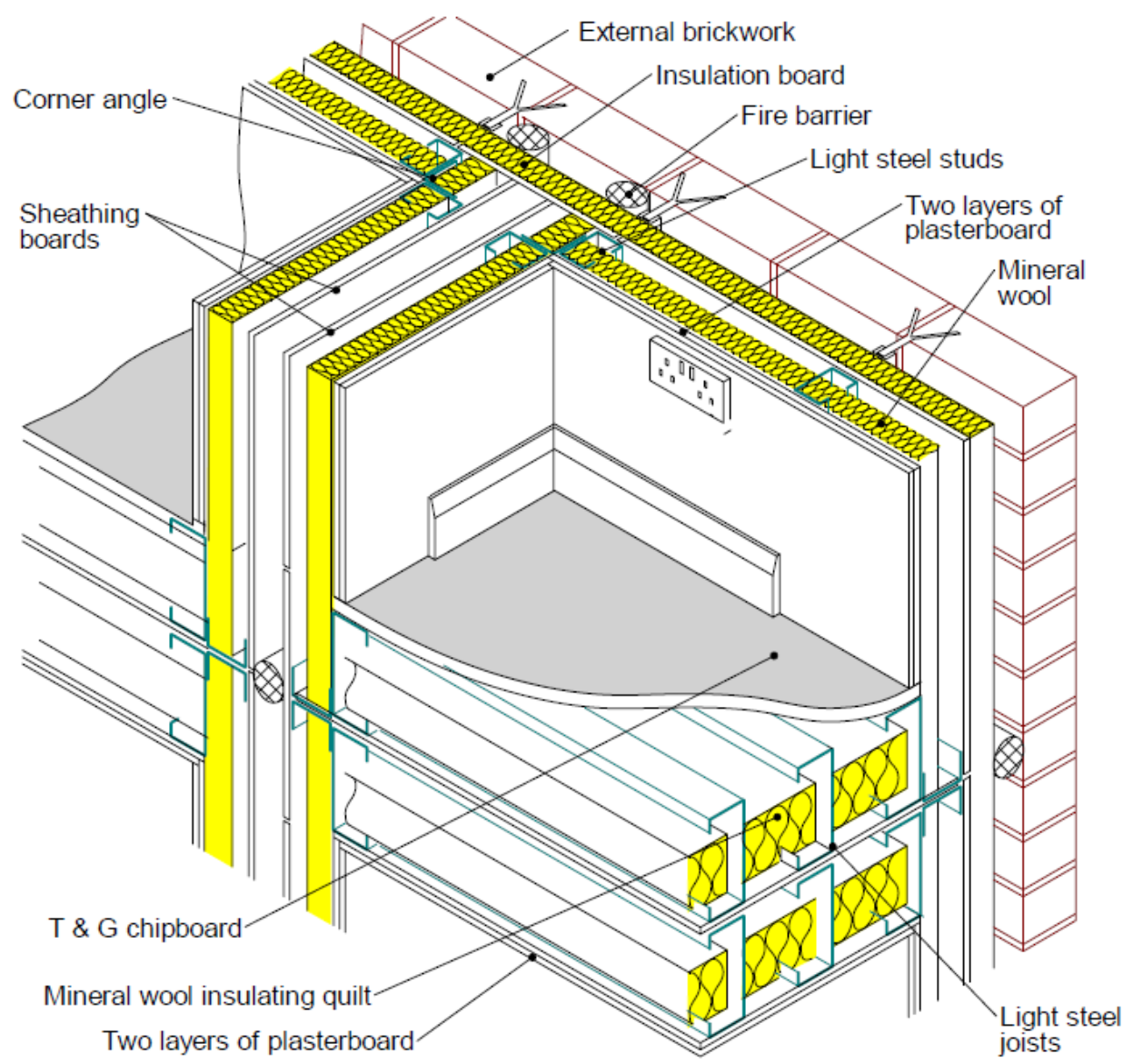

Figure 11. Typical fire protection and cavity barriers attached to light steel framing [17].

\section{Sustainability Benefits of Modular Constructions}

Sustainability benefits of modular construction are presented in terms of a combination of environmental, economic and social performances. Kamali and Hewage [51] have developed a system with most relevant indicators to evaluate the sustainability of a building under the aforementioned criteria by comparing modular and conventional construction. Table 4 describes indicators of each criterion.

Table 4. Indicators of sustainable performance [51].

\begin{tabular}{|c|c|c|}
\hline Performance & Indicator & Description \\
\hline \multirow{5}{*}{ Environmental } & Disruption in site & $\begin{array}{l}\text { Construction activities are causing disruption in sites such as } \\
\text { excavation, piling and structural works. Disruption of sites can be } \\
\text { minimized by proper site planning. }\end{array}$ \\
\hline & Waste generation & $\begin{array}{l}\text { Waste generated from construction activities. Effective material } \\
\text { planning and handling can reduce the wastage of materials in the site }\end{array}$ \\
\hline & Pollution & $\begin{array}{l}\text { Wastages, noise from machineries and dust will cause pollution. } \\
\text { Monitoring the pollution level and adopting innovative methods can } \\
\text { be viable solutions to minimize adverse effects to the environment. }\end{array}$ \\
\hline & Energy consumption & $\begin{array}{l}\text { Diesel for machineries and vehicles and electricity for tools in } \\
\text { construction activities. Energy consumption can be reduced by } \\
\text { efficient utilization of machineries and construction tools. }\end{array}$ \\
\hline & Water usage & $\begin{array}{l}\text { Water usage is essential in construction sites for various construction } \\
\text { activities including concrete production. Water can be used in an } \\
\text { efficient way to avoid over-consumption of ground water. }\end{array}$ \\
\hline
\end{tabular}


Table 4. Cont.

\begin{tabular}{|c|c|c|}
\hline Performance & Indicator & Description \\
\hline \multirow{6}{*}{ Economic } & Form-work amount & $\begin{array}{l}\text { Timber amounts for formwork purposes can be reused several times, } \\
\text { which will reduce the timber requirements for the site. }\end{array}$ \\
\hline & Cost effectiveness & $\begin{array}{l}\text { Cost savings in construction activities in terms of labour, machineries, } \\
\text { vehicles and materials. Cost planning, cost scheduling and cost } \\
\text { controlling processes will be considered to increase the savings. }\end{array}$ \\
\hline & Time & $\begin{array}{l}\text { Construction duration time from planning to completion which } \\
\text { depends on various factors such as availability of resources, weather } \\
\text { constraints and complexity of the project. }\end{array}$ \\
\hline & Labour & $\begin{array}{l}\text { Amount of construction activities and complexity and variety of } \\
\text { construction works will decide the number of labourers needed for } \\
\text { the project. }\end{array}$ \\
\hline & Executing cost & The costs of construction activity execution and operation on site. \\
\hline & Weather constraints & $\begin{array}{l}\text { Weather effects such as rain, snow and storms can cause unexpected } \\
\text { delays. Precautionary plans in terms of cost and safety should be } \\
\text { implemented to reduce the cost effects and schedule delays }\end{array}$ \\
\hline \multirow{5}{*}{ Social } & Ease of Constructability & $\begin{array}{l}\text { Constraints in terms of location, material transportation, labour } \\
\text { availability and the physical nature of the land (soil properties, } \\
\text { groundwater level and terrain) will influence the nature of the project } \\
\text { and will decide the effort that needed. }\end{array}$ \\
\hline & $\begin{array}{l}\text { Risks related to health and } \\
\text { safety }\end{array}$ & $\begin{array}{l}\text { Construction project includes safety and health risks for labourers. } \\
\text { Safety regulations and guidelines for labourers will reduce injuries } \\
\text { and fatalities. }\end{array}$ \\
\hline & Quality & $\begin{array}{l}\text { Quality of a construction project will be decided based on life cycle } \\
\text { performance. Mainly depends on durability performance against } \\
\text { constraints including weather. }\end{array}$ \\
\hline & Aesthetic options & $\begin{array}{l}\text { Visual appearance of internal and external of the building. Design } \\
\text { and cost will influence in the options. }\end{array}$ \\
\hline & Availability of human resource & $\begin{array}{l}\text { Employment opportunities available in a construction project. Project } \\
\text { type and budget will decide the number of employment } \\
\text { opportunities. }\end{array}$ \\
\hline
\end{tabular}

\subsection{Environment}

The influence of the construction industry on the environment is enormous, as it is responsible for $40 \%$ of global energy consumption, $28 \%$ of global greenhouse gas emissions, $12 \%$ of global potable water usage and $40 \%$ of solid waste generation from developed countries [63]. With the increasing concerns about sustainability and to overcome the high environmental effects caused by conventional construction, innovative construction methods are required. In particular, Modular Building Systems (MBS) have been related to a cost-effective solution that reduces resource demands, energy consumption, and $\mathrm{CO}_{2}$ emissions throughout the life cycle. Implementing design and structural optimization not only increases the freedom of design approaches, but also reduces the material usage in MBS. As a result, MBS functions better environmentally over the entire service life compared to conventional structures.

Jiang et al. [19] studied the sustainable performances of prefabrication with conventional building during the construction stage. It is proved that the prefabrication has noticeable sustainable performances compared to conventional building. Iuorio and Fiorio [1] investigated the environmental impacts of structural and non-structural components of a modular lightweight steel building during both the construction and the deconstruction phase using life cycle analysis. The study concludes that for a system, the structural modular components must be carefully chosen to maximize the thermal performance and to minimize the environmental 
impacts. The study also reveals that those effects on environment are partly counterbalanced by the recycling of components in the end-of-life phase.

Boyd et al. [64] and Boafo et al. [65] presented the benefits of off-site modular construction in terms of improved construction speed, quality of the structure and architecture, material efficiency and worker health and safety. Furthermore, Cao et al. [66] performed a comparative study of environmental performance between off-site modular and cast in situ construction. The comparison showed that off-site modular construction has obvious advantages in material consumption, energy use, and water discharge [19].

\subsection{Economic}

The construction industry contributes a share of $9 \%$ gross domestic product and about $7-8.5 \%$ of the total employment around the world for economic development, along with the other major industries [67-69]. However, the industry is still exemplified by low productivity with low technological advances [19]. Off-site modular construction technologies have replaced the ineffective on-site activities with more efficient faster factory manufacturing by bringing most of the fabrication away from the construction site. From an economic point of view, innovative MBS produces modifications in the stakeholders as well as in the cost structure. MBS is one of the significant factors which leads the construction sector towards a circular economy as MBS offers many potential prospects, such as disassemblability and reusability [70]. Buildings with mechanical connections could be designed with disassemblability in mind and materials can be directly added in the supply chain after the deconstruction of the building, which will enhance the efficiency of material utilization and cost effectiveness. Visible connections, steel frames and standard components are preferable for disassembly and reuse as those allow easy separation.

Although it is difficult to quantitatively present the cost structure, the key factors to be analysed during the economical potentials of MBS are: initial investment for offsite manufacturing, effectiveness of material usage, amount of on-site construction work, transportation and installation costs, speed of fabrication and cost reduction from on-site management [13]. Figure 12 shows an analysis of the costs of a building constructed with site intensive processes and modular construction.

\subsection{Social}

The lightweight modular components are developed as being modifiable; thus, those units are capable of being disassembled and reused. A report presented by 'The Steel Construction Institute, UK' [71] claims that the light steel framing and modular constructions have increased the productivity and speed of construction by over 30\%, which ultimately reduces adverse effects on site. Moreover, the site wastages in terms of construction materials have been eliminated by these pre-manufactured modular components by $10 \%$ compared to the conventional construction. Additionally, the report presents that the embodied carbon is reduced by $20 \%$ with the usage of modular steel framings. Tam and Hao [72] studied the effectiveness of prefabrication and MBS in terms of waste reduction compared to the traditional on-site construction. The conclusions indicate that wastage from deficient workmanship could be significantly lowered by implementing MBS in construction.

Since modular constructions hold significant sustainability benefits, development of novel sections is further required to enhance it sustainability performances. Hence, as a first step, back-to-back and closed built-up sections with screw arrangements are investigated in this study for the future development of innovative cold-formed steel sections in order to enhance the sustainability performances of modular constructions in the UK. Finite element modelling using ABAQUS software package [73], validation procedure and analysis results with open and closed built-up sections with various screw arrangements are presented in the following sections. 


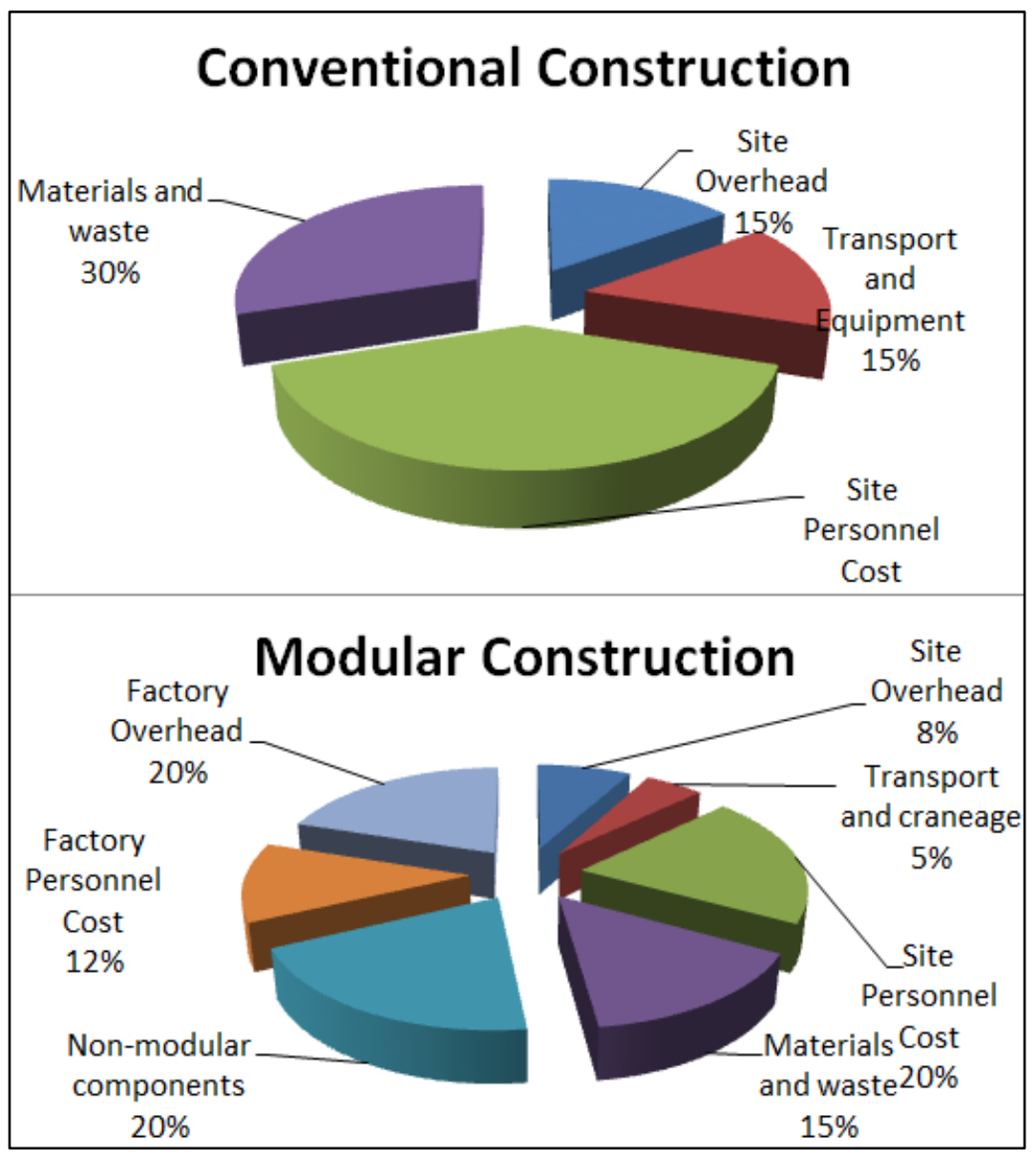

Figure 12. Comparison of overall costs of on-site and modular construction [13].

\section{Finite Element Modelling of Built-Up Sections and Validation}

\subsection{Model Development of Built-Up Sections with Various Screw Arrangements}

Non-linear analysis of built-up sections was carried out using the ABAQUS software package in this study. The cross-sectional dimensions and material parameters are illustrated in Section 6. Based on the cross-sectional dimensions $(231 \times 75 \times 17$ section with a corner radius of $3 \mathrm{~mm}$ and base thickness of $1.5 \mathrm{~mm}$ ), CFS built-up sections were modelled using S4R shell elements. In this study, $1626 \mathrm{~mm}$ of length was assigned to both the shear and moment spans to avoid the shear buckling in the shear span as well as to ensure the pure bending in mid span [74]. Mesh sizes of $5 \mathrm{~mm} \times 5 \mathrm{~mm}$ and $1 \mathrm{~mm} \times 5 \mathrm{~mm}$ were assigned to the flat regions and corner regions, respectively. Cross-section of the beam and mesh sizes are shown in Figure 13. Two different yield strengths such as $450 \mathrm{MPa}$ and $600 \mathrm{MPa}$ are assigned along with density, Poisson's ratio and elastic modulus.

The static general analysis with the specification of damping factor was used in this study following its validation. Interaction between contact surfaces of webs in back-to-back models whilst between flanges in closed models were defined with the surface-to-surface contact method with tangential and normal behaviours. Tangential behaviour was defined to be frictionless, whereas normal behaviour is defined as hard contact in this study. Further, loading and supporting boundary conditions were applied to the created reference points where each region was coupled to a reference point kinematically in all degrees of freedom. The coupled regions in both of the back-to-back and closed models are illustrated in Figures 14 and 15, respectively. Moreover, lateral restraints at $300 \mathrm{~mm}$ intervals were applied along the beam to avoid lateral torsional buckling. Applied boundary conditions are shown below in Figure 16. The screw arrangements in the web and flanges were 
incorporated by creating connectors with the MPC connection-type beam. Then, the screw connections were created and assigned to the connector assignment as well.

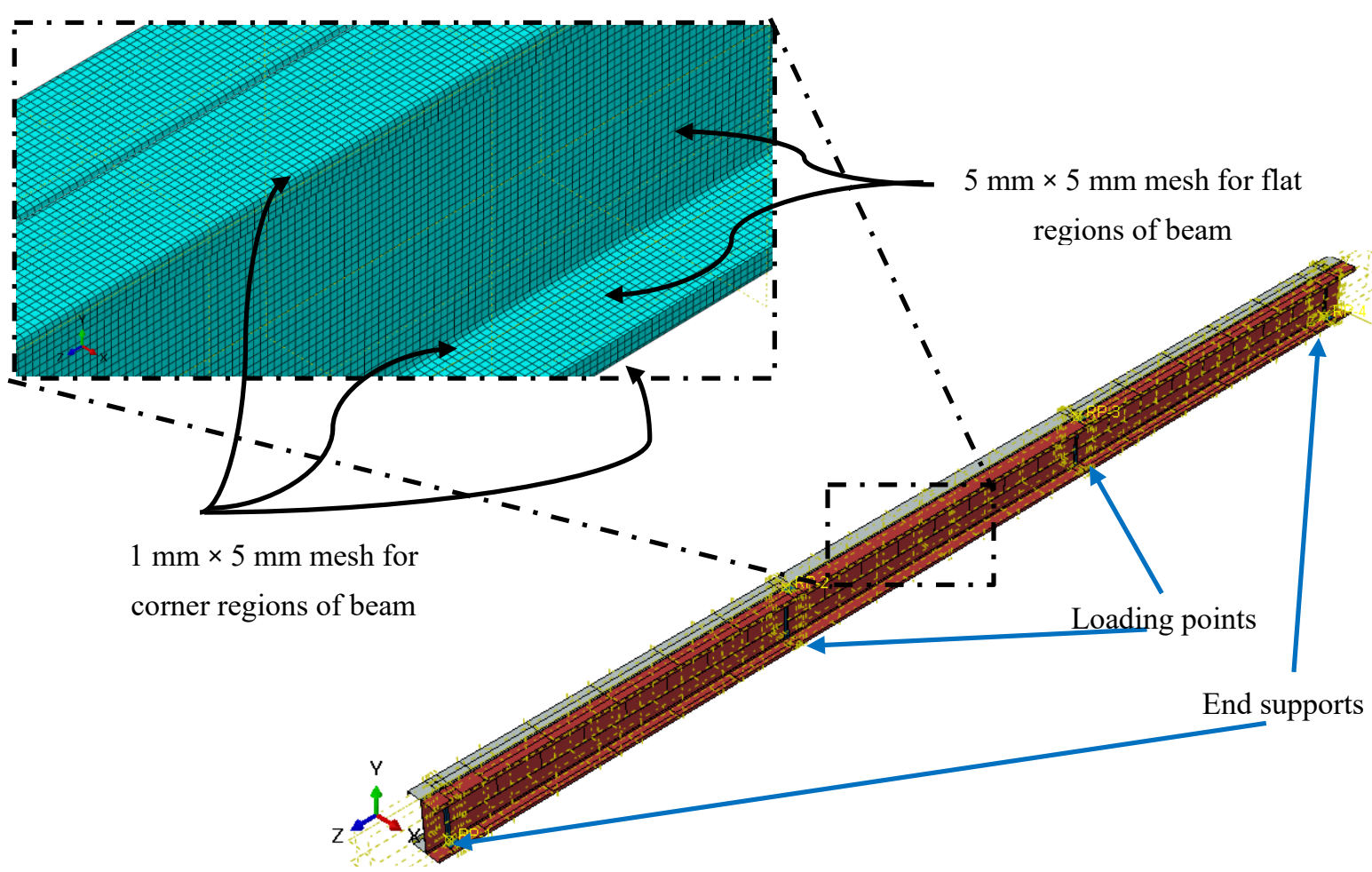

Figure 13. Mesh sizes of the analysis.

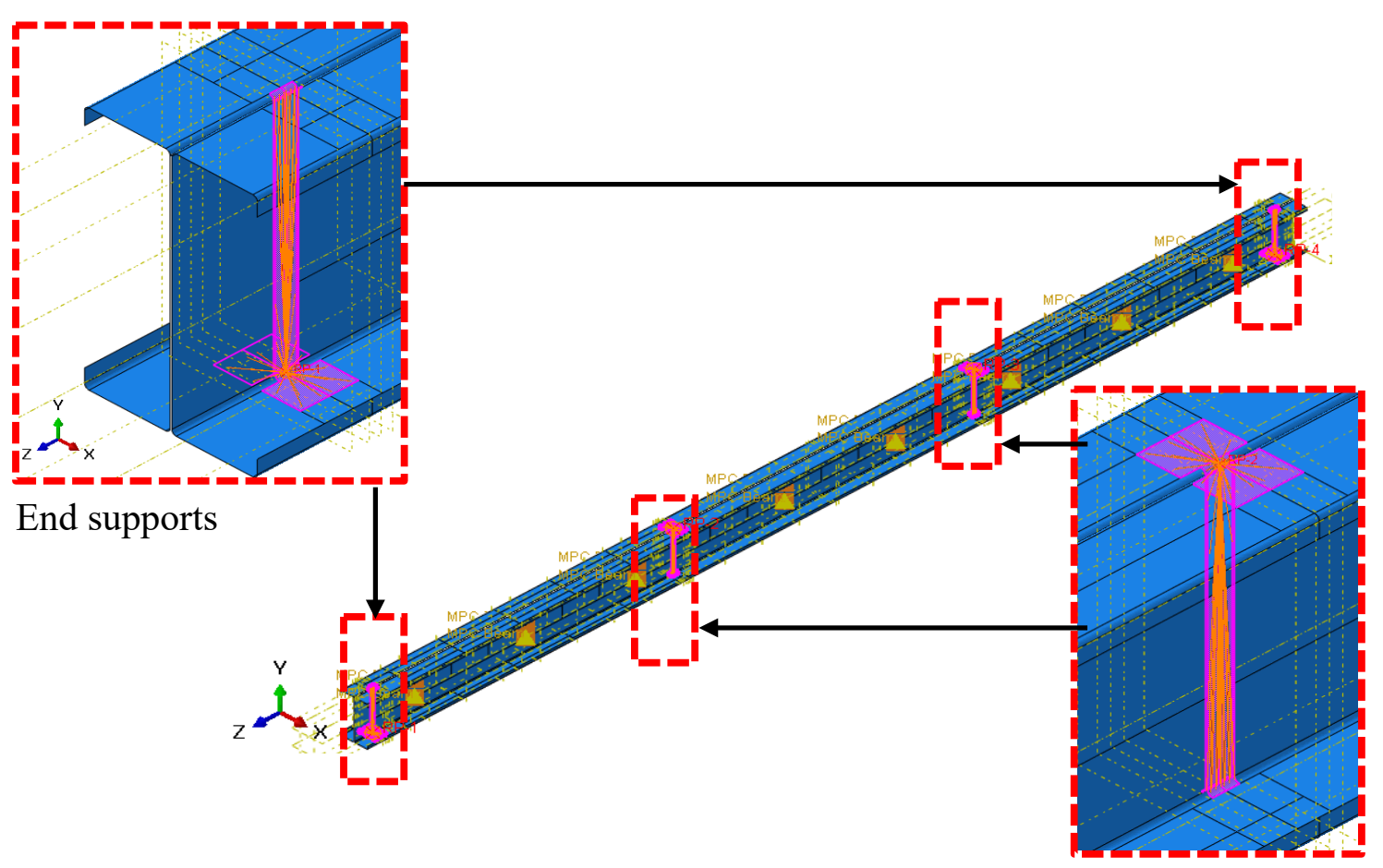

Loading points

Figure 14. Coupling at loading and supporting points of open built-up beams. 


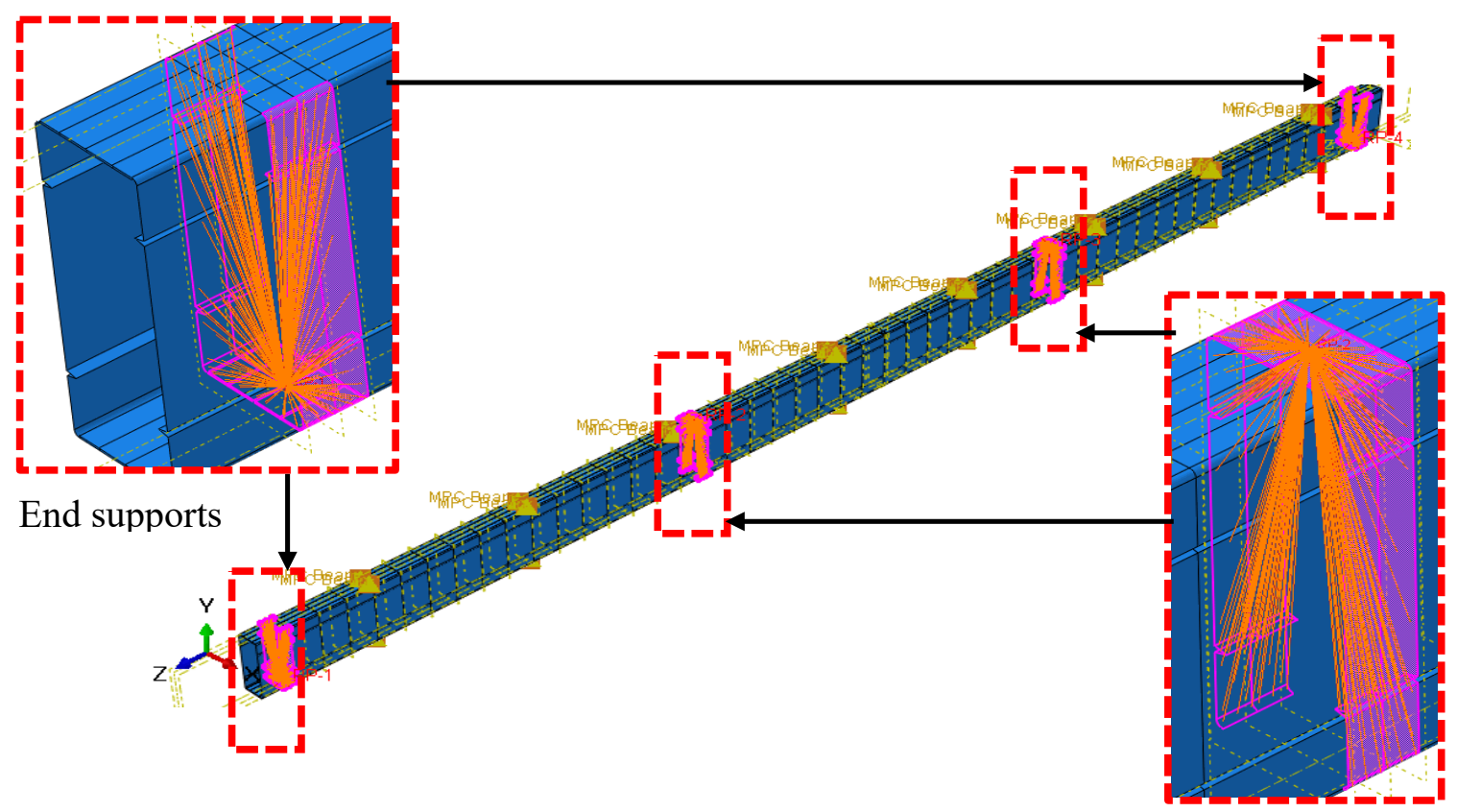

Loading points

Figure 15. Coupling at loading and supporting points of closed built-up beams.

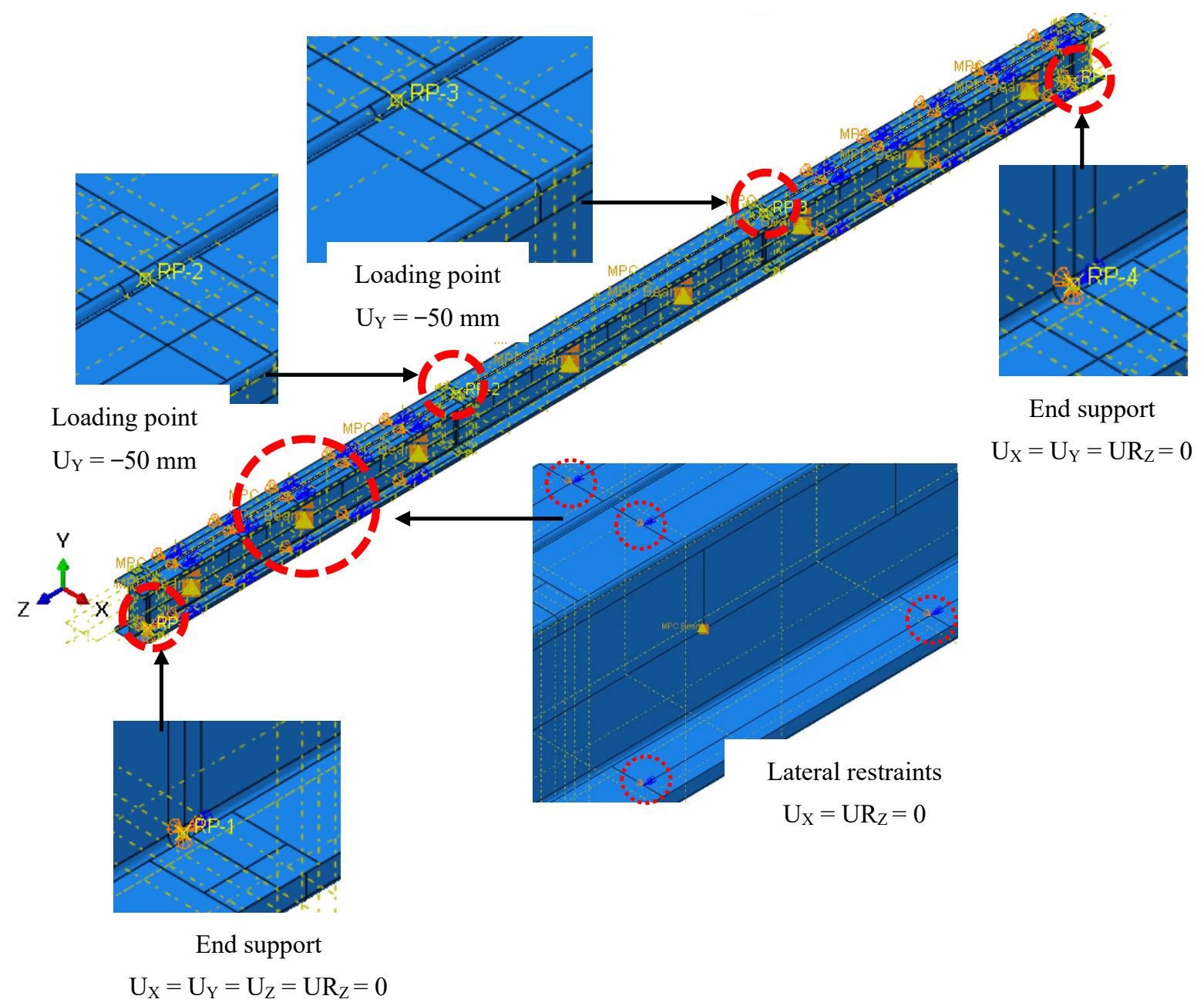

Figure 16. Boundary conditions at loading, supporting and strap points. 
Initial geometric imperfection was added by incorporating buckling analysis on the same model. The eigenvalue was extracted from buckling analysis and used with *IMPERFECTION in the non-linear model to introduce the imperfection. Finally, flexural capacity is obtained from the non-linear model.

\subsection{Validation of Finite Element Models}

Wang and Young [47] conducted four-point bending tests on cold-formed steel builtup open and closed sections, and these experimental results were considered for the validation process in this study. Altogether, sixteen test results were used to verify the developed FE models. Tables 5 and 6 compare the experimental and FE ultimate moment capacities of cold-formed steel built-up open sections and closed sections, respectively. The experimental-to-FE moment capacity ratio $\left(\mathrm{M}_{\mathrm{Exp}} / \mathrm{M}_{\mathrm{FE}}\right)$ has a mean value of 0.98 and a coefficient of variation (COV) of 0.047 for open sections, whilst closed sections predicted a mean value of 1.00 and a COV of 0.03 . Therefore, a good agreement was noticed between the moment capacities. The dominant failure mode of each specimen observed at the failure is also included in Tables 5 and 6 for both experiments and FE models. The interaction of two buckling modes, distortional (D) and local (L), has been observed for the first seven specimens of validation, whilst distortional (D) has been observed in last two experiments of built-up open sections, and this is also confirmed by the numerical results. Meanwhile, for closed sections, local (L) has been observed during experimental and numerical studies.

Table 5. Comparison of experimental [47] and FE moment capacities and failure modes of cold formed steel built-up open sections.

\begin{tabular}{|c|c|c|c|c|c|c|}
\hline \multirow[b]{2}{*}{ No. } & \multirow[b]{2}{*}{ Specimens } & \multicolumn{2}{|c|}{ Experiment } & \multicolumn{2}{|c|}{ FE } & \multirow[b]{2}{*}{$\mathbf{M}_{\mathrm{Exp}} / \mathbf{M}_{\mathrm{FE}}$} \\
\hline & & $\begin{array}{c}M_{\operatorname{Exp}} \\
(\mathbf{k N m})\end{array}$ & $\begin{array}{l}\text { Failure } \\
\text { Mode }\end{array}$ & $\underset{(\mathrm{kNm})}{\mathrm{M}_{\mathrm{FE}}}$ & $\begin{array}{l}\text { Failure } \\
\text { Mode }\end{array}$ & \\
\hline 1 & СТ0.42-86-S75 & 0.796 & $\mathrm{~L}$ & 0.770 & $\mathrm{~L}$ & 1.03 \\
\hline 2 & CT0.42-86-S150 & 0.796 & $\mathrm{~L}$ & 0.771 & $\mathrm{~L}$ & 1.03 \\
\hline 3 & CT0.42-86-S300 & 0.735 & $\mathrm{~L}$ & 0.760 & $\mathrm{~L}$ & 0.97 \\
\hline 4 & CT1.9-86-S300 & 7.803 & $\mathrm{~L}$ & 8.044 & $\mathrm{~L}$ & 0.97 \\
\hline 5 & CT1.2-136-S150 & 7.553 & $\mathrm{~L}$ & 7.730 & $\mathrm{~L}$ & 0.98 \\
\hline 6 & CT1.2-136-S300 & 7.348 & $\mathrm{~L}$ & 7.535 & $\mathrm{~L}$ & 0.98 \\
\hline \multirow[t]{3}{*}{7} & CT1.2-136-S600 & 7.053 & $\mathrm{~L}$ & 7.112 & $\mathrm{~L}$ & 0.99 \\
\hline & \multicolumn{3}{|c|}{ Mean } & & & 1.00 \\
\hline & \multicolumn{3}{|c|}{$\mathrm{COV}$} & & & 0.03 \\
\hline
\end{tabular}

Note: Specimen notations are as in Wang and Young [47], D—distortional buckling, L—local buckling, $\mathrm{M}_{\mathrm{Exp}}$ —experimental moment capacity and $\mathrm{M}_{\mathrm{FE}}$-finite element modelling moment capacity.

Table 6. Comparison of experimental [47] and FE moment capacities and failure modes of coldformed steel built-up closed sections.

\begin{tabular}{ccccccc}
\hline & & \multicolumn{2}{c}{ Experiment } & \multicolumn{2}{c}{ FE } & \\
\cline { 3 - 6 } No. & Specimen & $\begin{array}{c}\mathbf{M}_{\text {Exp }} \\
(\mathbf{k N m})\end{array}$ & $\begin{array}{c}\text { Failure } \\
\text { Mode }\end{array}$ & $\begin{array}{c}\mathbf{M}_{\mathbf{F E}} \\
\mathbf{( k N m )}\end{array}$ & $\begin{array}{c}\text { Failure } \\
\text { Mode }\end{array}$ & $\mathbf{M}_{\text {Exp }} / \mathbf{M}_{\mathbf{F E}}$ \\
\hline 1 & OT0.42-86-S75 & 1.206 & $\mathrm{D}+\mathrm{L}$ & 1.294 & $\mathrm{D}+\mathrm{L}$ & 0.93 \\
2 & OT0.42-86-S300 & 1.222 & $\mathrm{D}+\mathrm{L}$ & 1.321 & $\mathrm{D}+\mathrm{L}$ & 0.93 \\
3 & OT1.2-86-S75 & 7.417 & $\mathrm{D}+\mathrm{L}$ & 7.230 & $\mathrm{D}+\mathrm{L}$ & 1.03 \\
4 & OT1.2-86-S75R1 & 7.303 & $\mathrm{D}+\mathrm{L}$ & 7.062 & $\mathrm{D}+\mathrm{L}$ & 1.03 \\
5 & OT1.2-86-S75R1-R & 7.341 & $\mathrm{D}+\mathrm{L}$ & 7.012 & $\mathrm{D}+\mathrm{L}$ & 1.05 \\
6 & OT1.2-86-S300 & 7.030 & $\mathrm{D}+\mathrm{L}$ & 7.366 & $\mathrm{D}+\mathrm{L}$ & 0.95 \\
7 & OT1.2-136-S150 & 12.240 & $\mathrm{D}+\mathrm{L}$ & 12.378 & $\mathrm{D}+\mathrm{L}$ & 0.99 \\
8 & OT1.9-136-S150 & 22.796 & $\mathrm{D}$ & 23.178 & $\mathrm{D}$ & 0.98 \\
\hline
\end{tabular}


Table 6. Cont.

\begin{tabular}{|c|c|c|c|c|c|c|}
\hline \multirow[b]{2}{*}{ No. } & \multirow[b]{2}{*}{ Specimen } & \multicolumn{2}{|c|}{ Experiment } & \multicolumn{2}{|c|}{ FE } & \multirow[b]{2}{*}{$\mathbf{M}_{\mathrm{Exp}} / \mathbf{M}_{\mathrm{FE}}$} \\
\hline & & $\begin{array}{c}\mathrm{M}_{\mathrm{Exp}} \\
(\mathbf{k N m})\end{array}$ & $\begin{array}{l}\text { Failure } \\
\text { Mode }\end{array}$ & $\begin{array}{c}\mathrm{M}_{\mathrm{FE}} \\
(\mathrm{kNm})\end{array}$ & $\begin{array}{l}\text { Failure } \\
\text { Mode }\end{array}$ & \\
\hline 9 & OT1.9-136-S300 & 22.159 & $\begin{array}{l}\text { Dan } \\
\text { ea }\end{array}$ & 23.401 & $\mathrm{D}$ & $\begin{array}{c}0.95 \\
0.98 \\
0.047\end{array}$ \\
\hline
\end{tabular}

Note: Specimen notations are as in Wang and Young [47], L-local buckling, $\mathrm{M}_{\mathrm{Exp}}$-experimental moment capacity and $\mathrm{M}_{\mathrm{FE}}$ - finite element modelling moment capacity.

The experimental and FE failure modes of cold-formed steel built-up open section OT1.9-136-S150 and OT1.9-136-S300 are illustrated in Figure 17. Similarly, FE failure modes comparison of cold-formed steel built-up closed section CT1.2-136-S150, CT1.2-136-S300 and CT1.2-136-S600 are illustrated in Figure 18. Since failure modes were observed to be similar from both experimental and FE failure modes, it can be concluded that the developed FE models well predict the failure mechanisms of built-up sections.

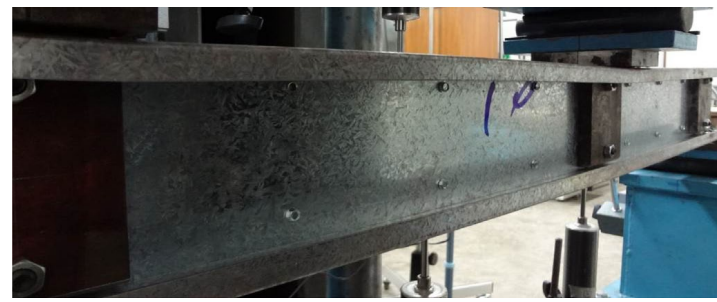

(a) Failure mode of OT1.9-136-S150 [47]

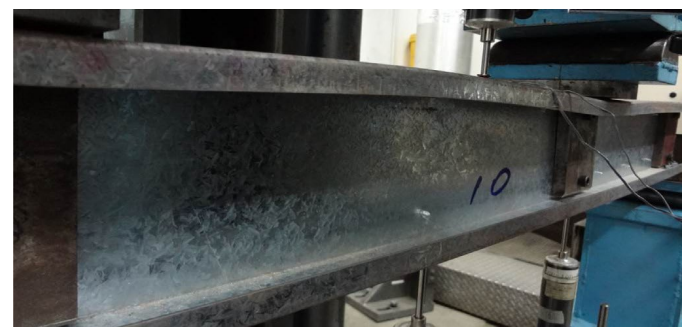

(c) Failure mode of OT1.9-136-S150 [47]

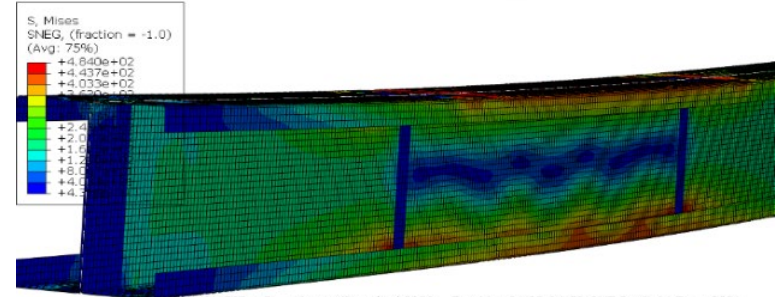

(b) Failure mode of OT1.9-136-S150

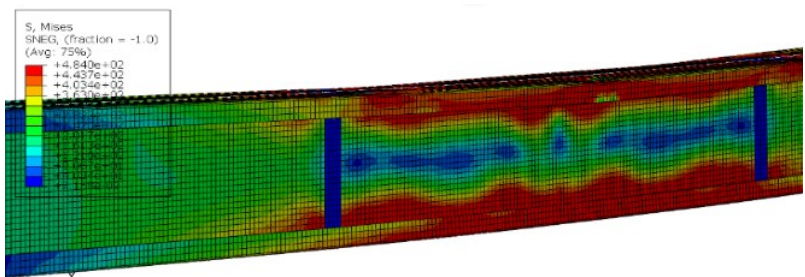

(d) Failure mode of OT1.9-136-S150

Figure 17. Comparison of experimental [47] and FE failure modes for cold-formed steel built-up open section OT1.9-136-S150 and OT1.9-136-S300.

The experimental and FE moment-curvature curves are also plotted in Figures 19 and 20 for the cold-formed steel built-up open section OT1.2-136-S150 and closed section CT1.986-S300. A good agreement was observed between two curves. Therefore, the behaviour of cold-formed built-up open and closed sections including the initial stiffness and moment and curvature at the failure of the specimen is predicted from the developed FE models with a good accuracy. Therefore, the same modelling procedure was followed in the investigation of flexural behaviour of built-up sections with various screw arrangements. 


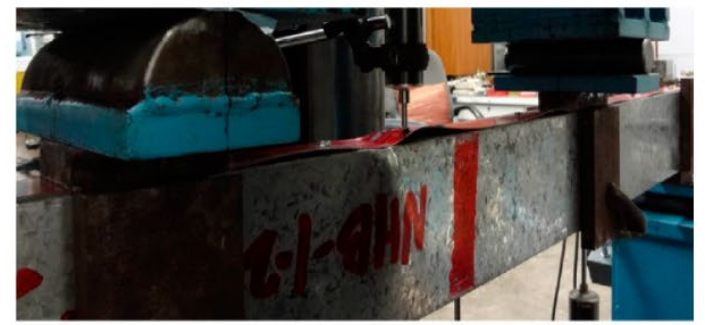

(a) Failure mode of CT1.2-136-S150 [47]

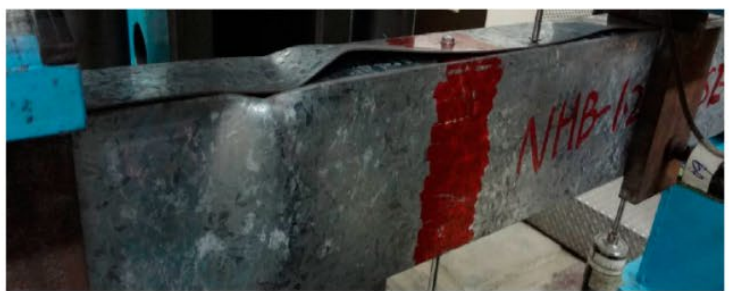

(c) Failure mode of CT1.2-136-S300 [47]

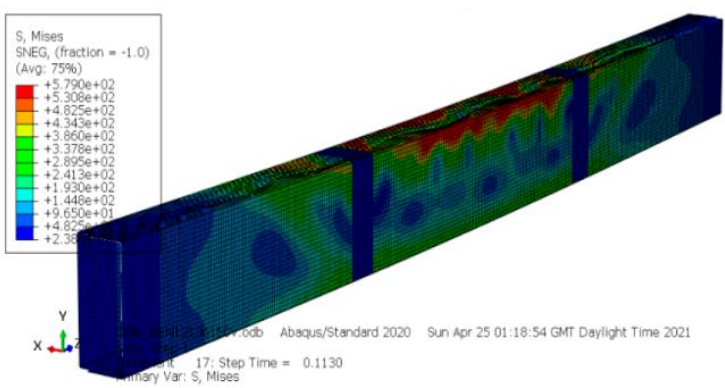

(b) Failure mode of CT1.2-136-S150

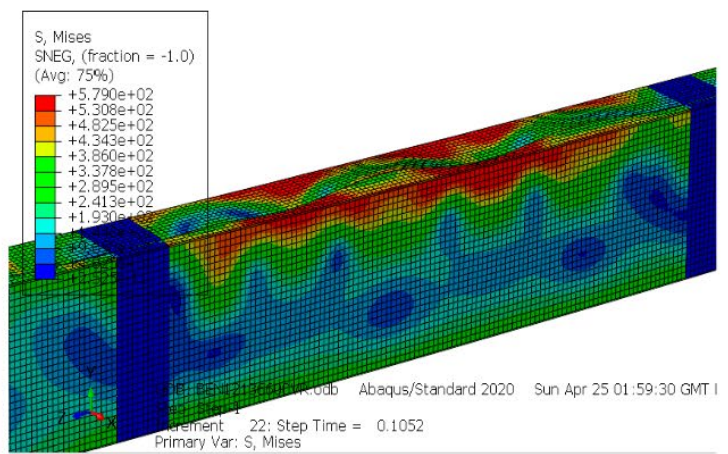

(d) Failure mode of CT1.2-136-S300

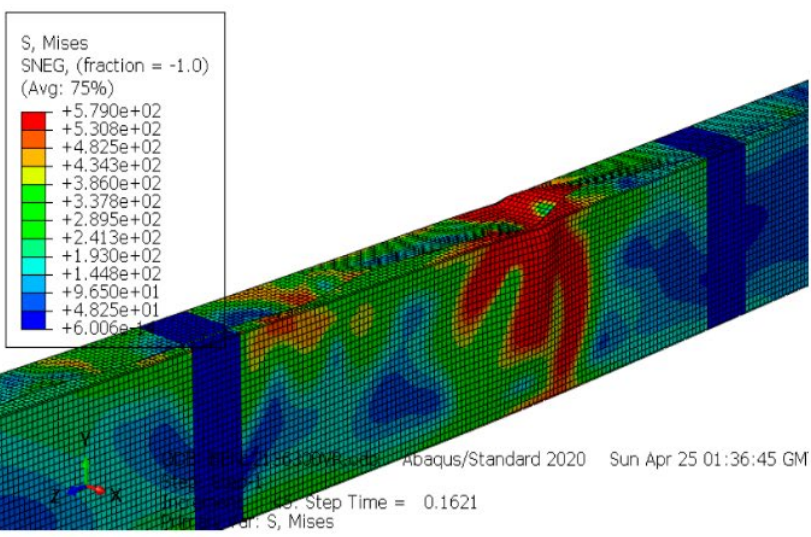

(f) Failure mode of CT1.2-136-S600

(e) Failure mode of CT1.2-136-S600 [47]

Figure 18. Comparison of experimental [47] and FE failure modes for cold-formed steel built-up closed section CT1.2-136S150, CT1.2-136-S300 and CT1.2-136-S600. 


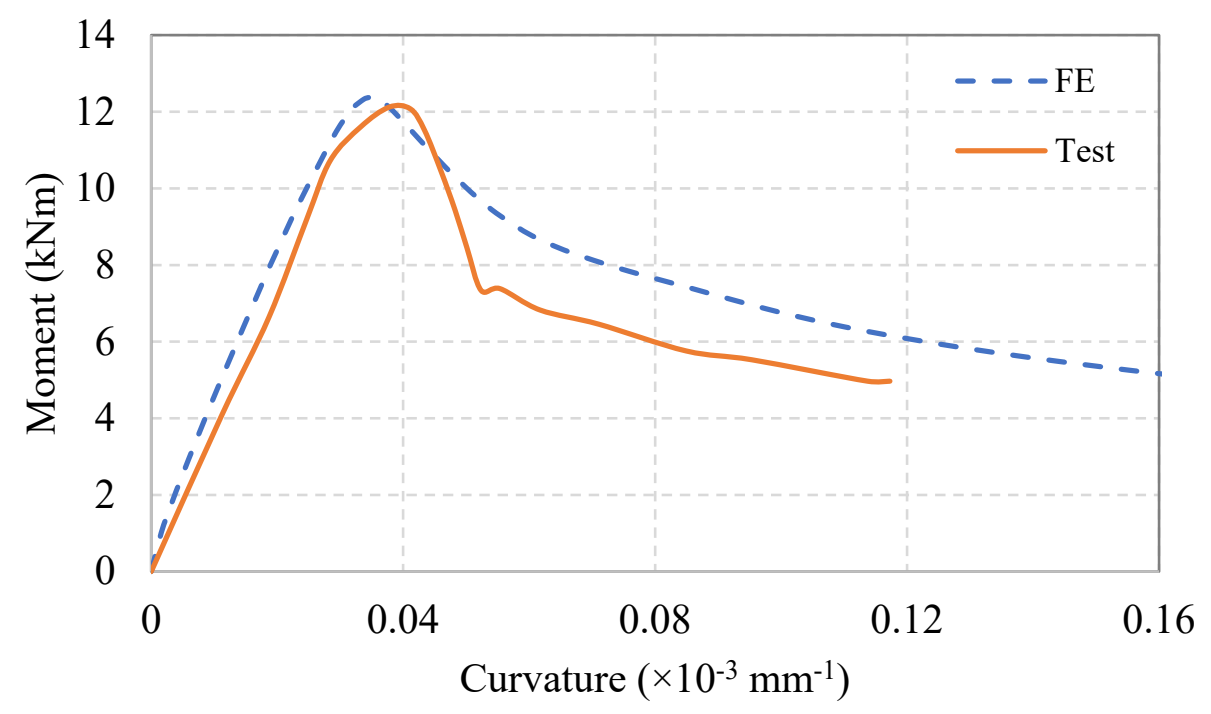

Figure 19. Comparison of experimental [47] and FE moment-curvature curves for cold-formed steel built-up open section OT1.2-136-S150.

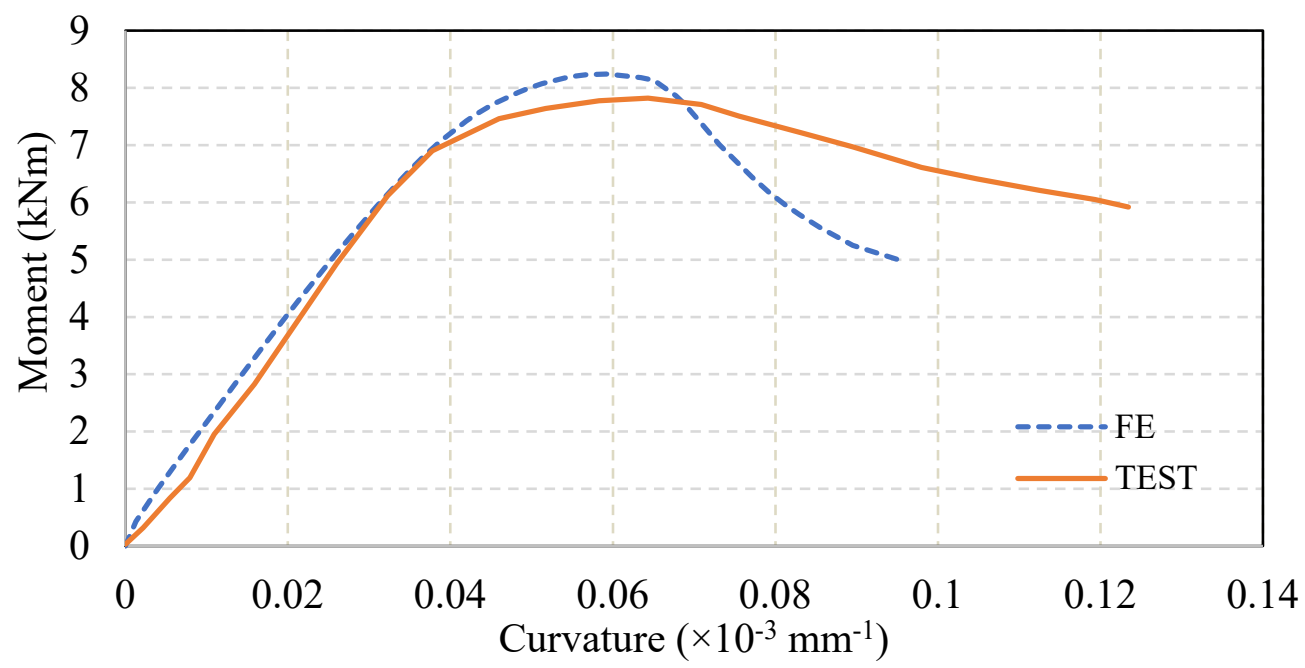

Figure 20. Comparison of experimental [47] and FE moment-curvature curves for cold-formed steel built-up closed section CT1.9-86-S300.

\section{Flexural Performance of Built-Up Sections}

Lipped channel sections used by Gatheesghar et al. [35] were selected in this study to investigate the flexural behaviour of built-up sections with different screw arrangements. First, back-to-back models were created using lipped channel sections whilst unlipped channel sections with intermediate stiffeners in web were chosen for closed models. The sections used for the back-to-back and closed models are shown in Figure 21. The stiffeners in the web element were introduced to unlipped channel sections (closed models) to cover the similar coil length of lipped channel sections. All the sectional dimensions including screw spacing used for the investigation of flexural performance are illustrated in Figure 21. The screws in open built-up sections were placed in the web at a distance of $0.3 \mathrm{~d}(0.3$ times the depth of the beam) from both flanges (Figure 21b). The spacing between screws in the longitudinal direction was changed to $50 \mathrm{~mm}, 100 \mathrm{~mm}, 200 \mathrm{~mm}$ and $600 \mathrm{~mm}$. In the meantime, two various screw arrangements were considered in the investigation of closed built-up sections. First, one screw at the middle of both flanges was connected in the longitudinal direction and then two screws in the distance of $15 \mathrm{~mm}$ from both end of the closed sections at both flanges were placed as shown in Figure 21d,e, respectively. 
The longitudinal distance between screws was changed as $100 \mathrm{~mm}$ and $600 \mathrm{~mm}$ for closed built-up sections. The parameters chosen in this study for both the open and closed studies are illustrated in Table 7 . In total, 16 parametric models were investigated covering single and built-up lipped and unlipped channel sections with various screw arrangements including two different yield strengths. The models were generated and analysed following the validation.

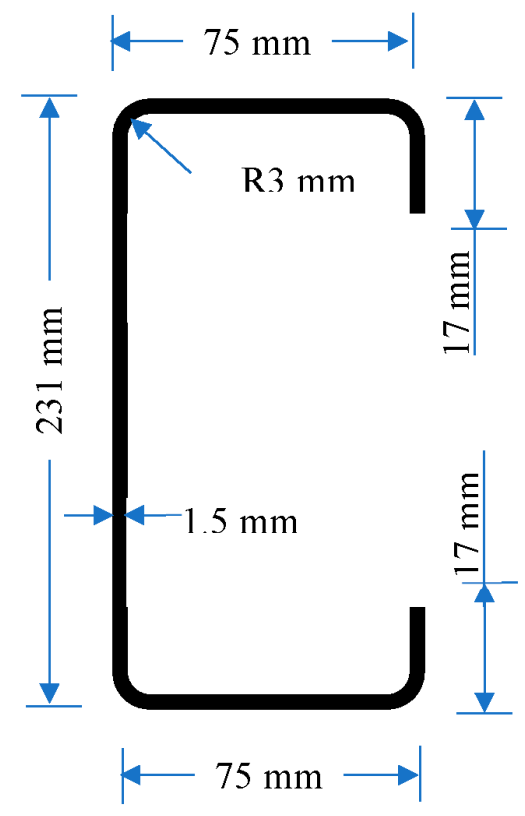

(a) Single lipped channel section

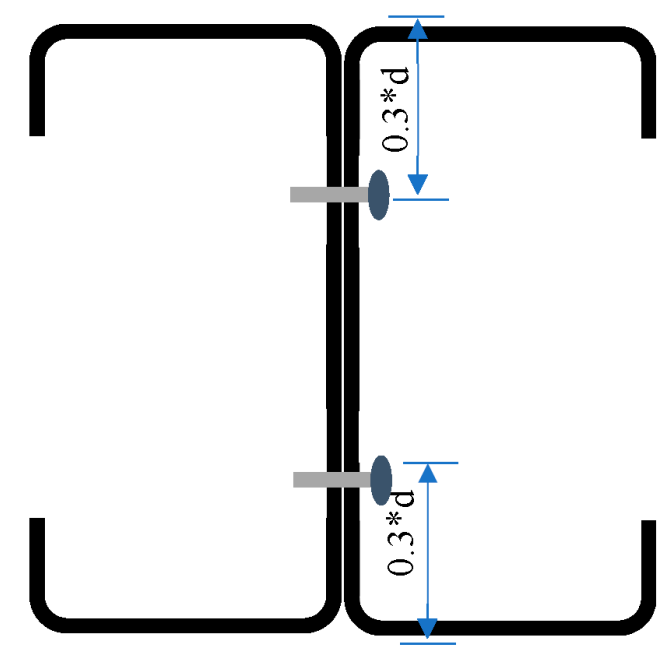

(b) Built-up open section

(i) Built-up open section

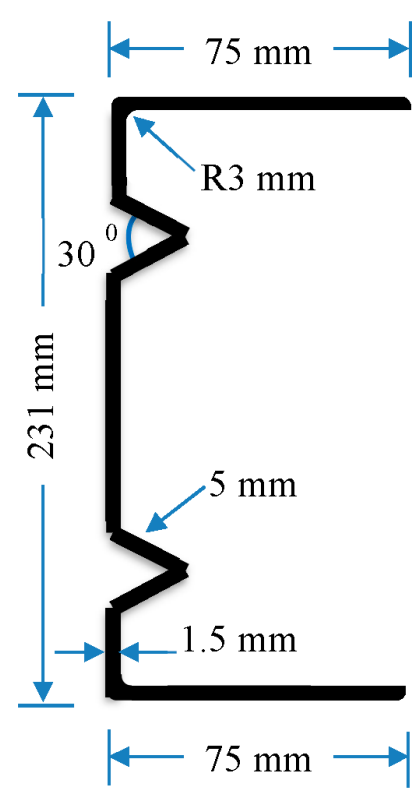

(c) Single unlipped channel section
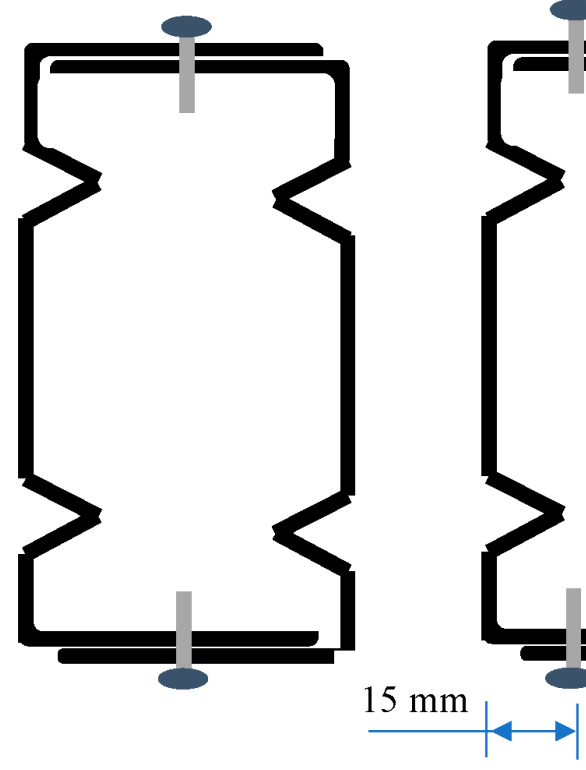

(e) Built-up close section

with double screws

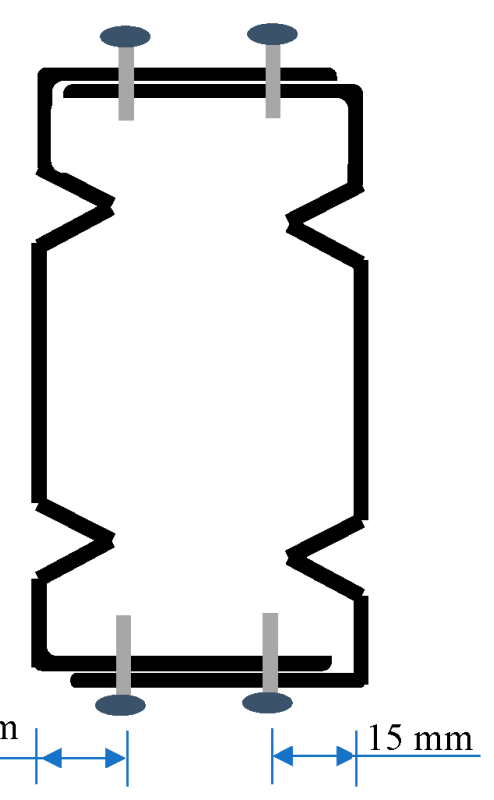

(d) Built-up close section with single screw

(ii) Built-up close section

Figure 21. Sectional dimensions of open and closed built-up models. 
Table 7. Parametric study.

\begin{tabular}{|c|c|c|c|c|}
\hline Specifications & $\begin{array}{l}\text { Strength } \\
\text { (MPa) }\end{array}$ & $\begin{array}{l}\text { Longitudinal Screw } \\
\text { Spacing }(\mathrm{mm})\end{array}$ & Model Types & Total \\
\hline $\begin{array}{l}\text { Open built-up section with } \\
\text { lipped channel beams }\end{array}$ & 450,600 & $50,100,200,600$ & $\begin{array}{c}\text { Single, } \\
\text { Back-to-back built-up sections } \\
\text { with screw arrangement }\end{array}$ & 8 \\
\hline $\begin{array}{l}\text { Closed built-up section with } \\
\text { unlipped channel beams }\end{array}$ & 450,600 & 100,600 & $\begin{array}{c}\text { Single, } \\
\text { Closed built-up sections with } \\
\text { two various screw arrangement }\end{array}$ & 8 \\
\hline \multicolumn{4}{|c|}{ Total } & 16 \\
\hline
\end{tabular}

\subsection{Open Built-Up Models and Results Analysis}

Since open built-up models are analysed using lipped channel sections, single models with $450 \mathrm{MPa}, 600 \mathrm{MPa}$ yield strengths were created with the sectional parameters as illustrated in Figure 21a, and flexural behaviour was observed for single models. Back-toback built-up models were created with a longitudinal screw spacing of $50 \mathrm{~mm}, 100 \mathrm{~mm}$, $200 \mathrm{~mm}$ and $600 \mathrm{~mm}$ in order to compare the capacity enhancement for built-up models with single models, as well as to observe the effect of screw spacing in the flexural behaviour of open built-up models. Bending moment vs. vertical displacement curve was observed for all open models, and failure modes at various stages were investigated during the study. The bending moment-vertical displacement curve of a single lipped channel section with $600 \mathrm{MPa}$ and corresponding failure modes at initial, before failure, during failure and post-failure stages are given in Figure 22. Similarly, the failure modes and graph for built-up open model with $100 \mathrm{~mm}$ spacing is also given in Figure 23. Figures 22 and 23 depict that the beams fail at the top flange and then web fails at the post-failure stage.

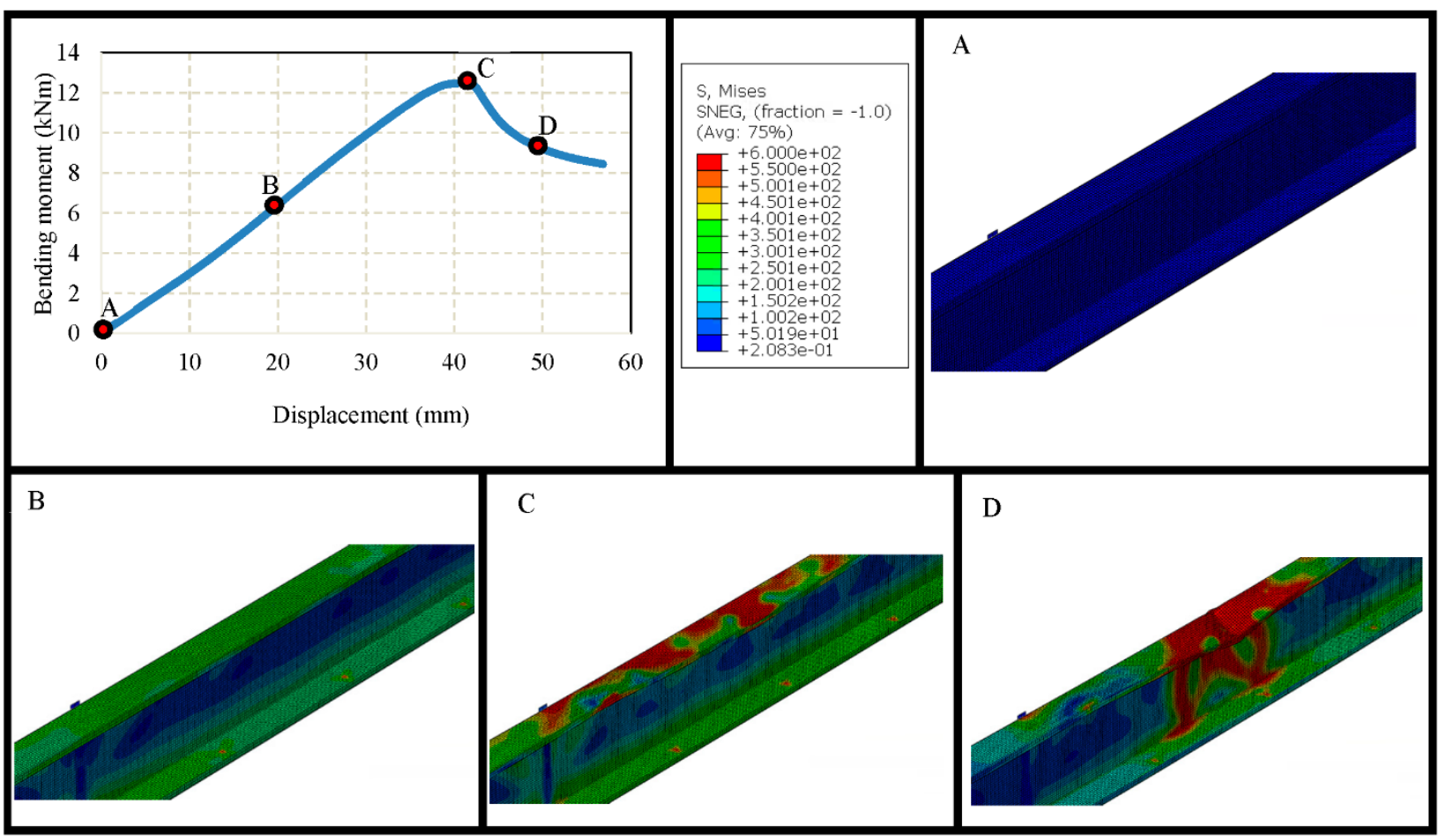

Figure 22. Failure modes and moment-displacement curve of lipped channel sections with $600 \mathrm{MPa}$ of yield strength. 


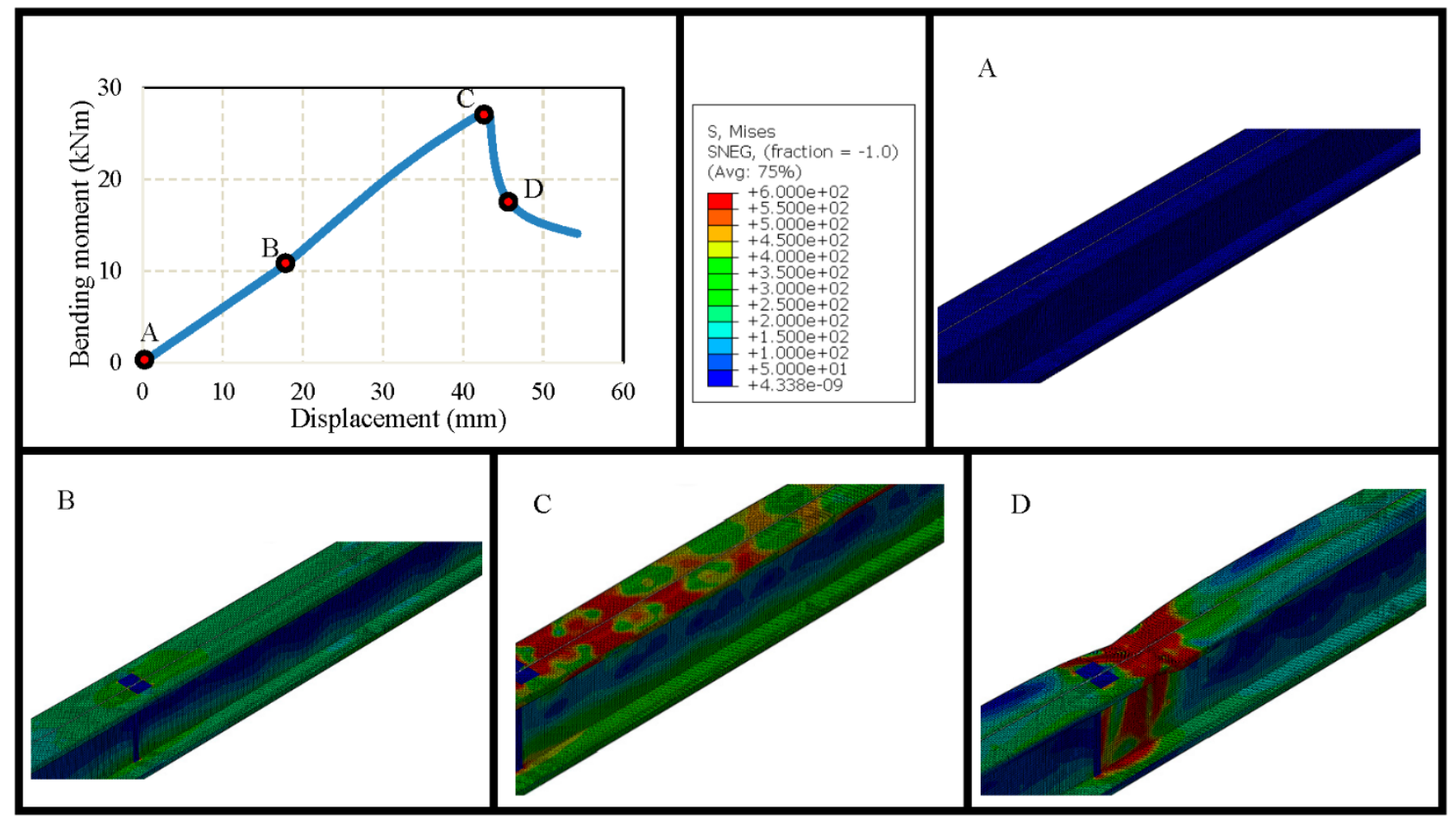

Figure 23. Failure modes and moment-displacement curve of open built-up model with $100 \mathrm{~mm}$ spacing and $600 \mathrm{MPa}$ of yield strength.

The flexural capacity of single sections with open built-up sections of $50 \mathrm{~mm}, 100 \mathrm{~mm}$, $200 \mathrm{~mm}$ and $600 \mathrm{~mm}$ of longitudinal screw spacing were compared and illustrated below in Figure 24. It is noticed that only a 2.11-, 2.10-, 2.10- and 2.08-times increment was witnessed compared to the single section for $50 \mathrm{~mm}, 100 \mathrm{~mm}, 200 \mathrm{~mm}$ and $600 \mathrm{~mm}$ of longitudinal screw spacing, respectively, when the yield strength was $450 \mathrm{MPa}$. Similarly, for $600 \mathrm{MPa}$, a 2.21-, 2.20-, 2.20- and 2.20-times increment was observed for $50 \mathrm{~mm}, 100 \mathrm{~mm}, 200 \mathrm{~mm}$ and $600 \mathrm{~mm}$ of longitudinal screw spacing, respectively. It is concluded that there is no noticeable influence noticed due to the longitudinal screw spacing on the flexural strength of built-up open sections. The bending moment-vertical displacement curve comparison for open built-up sections with screw spacings of $50 \mathrm{~mm}, 100 \mathrm{~mm}, 200 \mathrm{~mm}$ and $600 \mathrm{~mm}$ and respective failure modes are compared in Figure 25 as well.

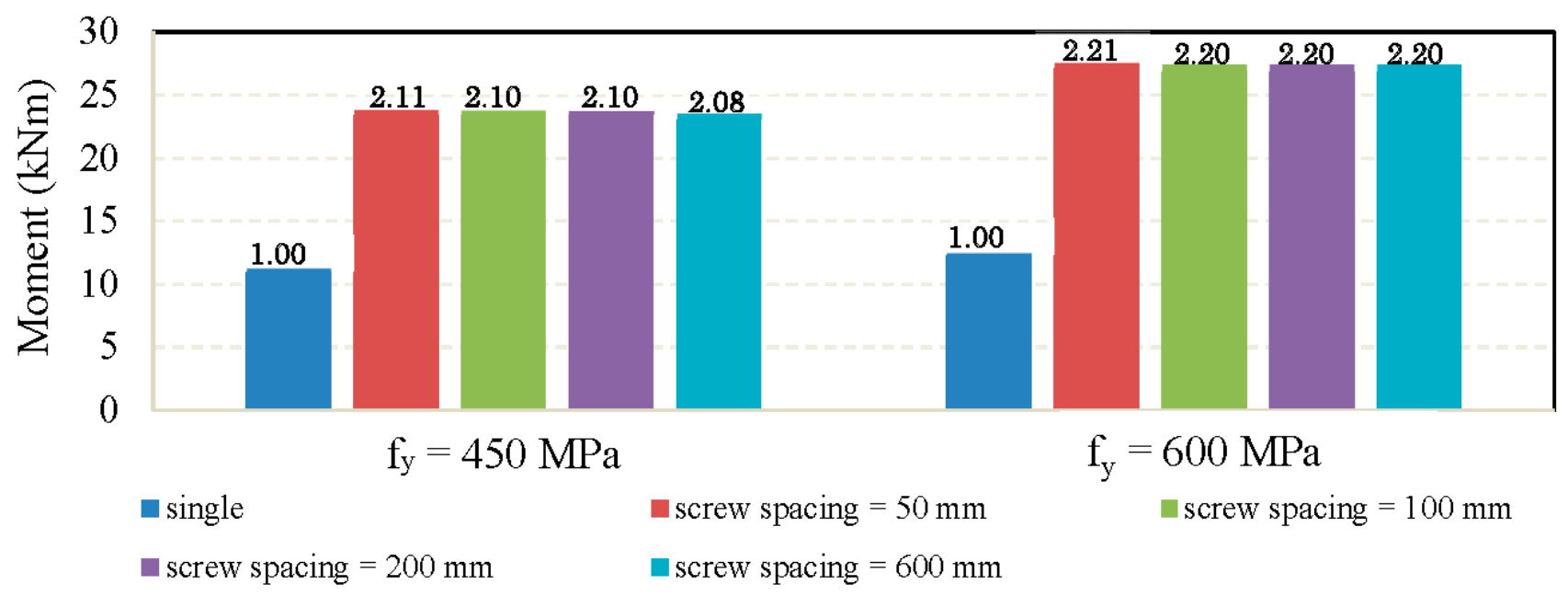

Figure 24. Flexural capacity comparison for open built-up sections. 


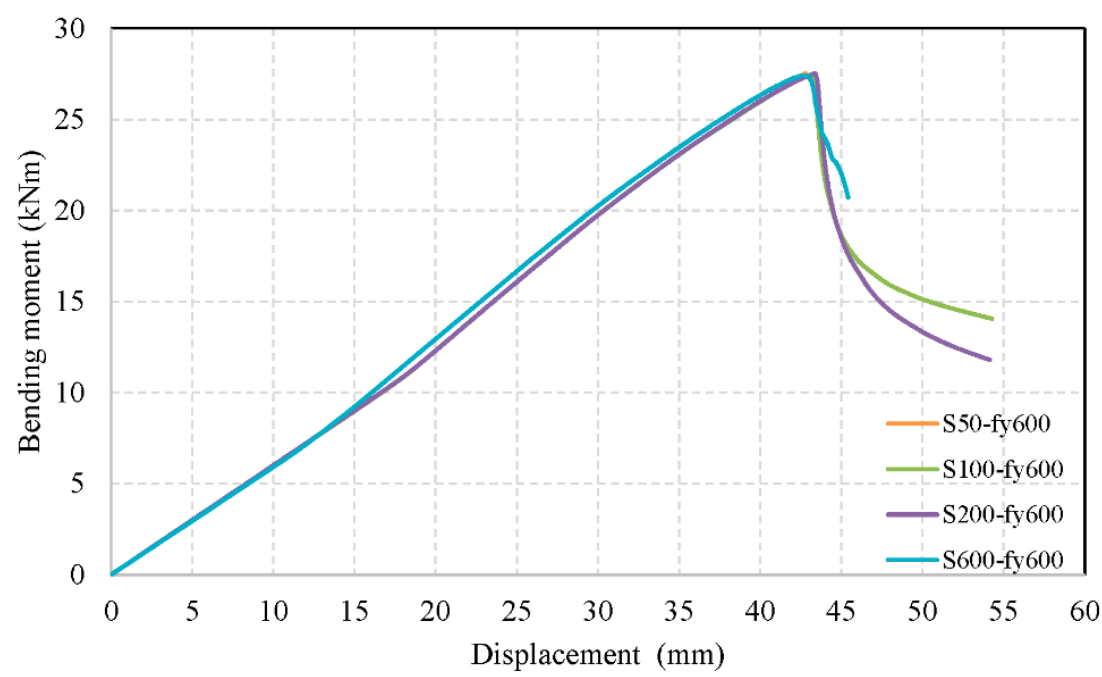

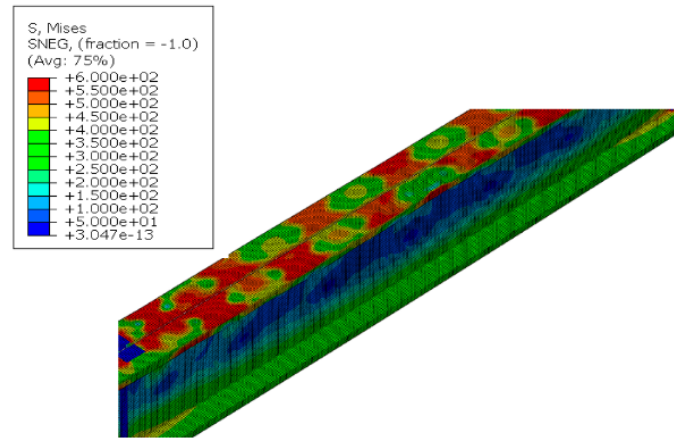

(a) S50-fy600

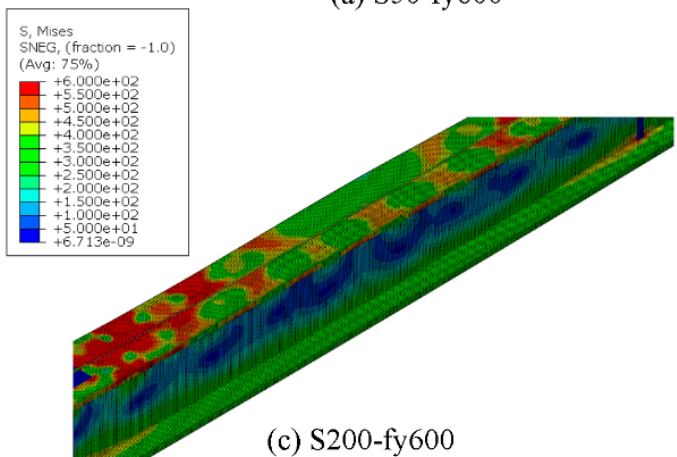

(c) S200-fy600

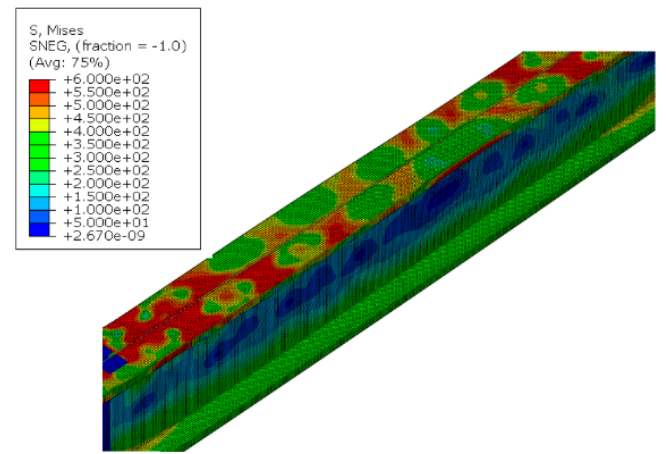

(b) S100-fy600

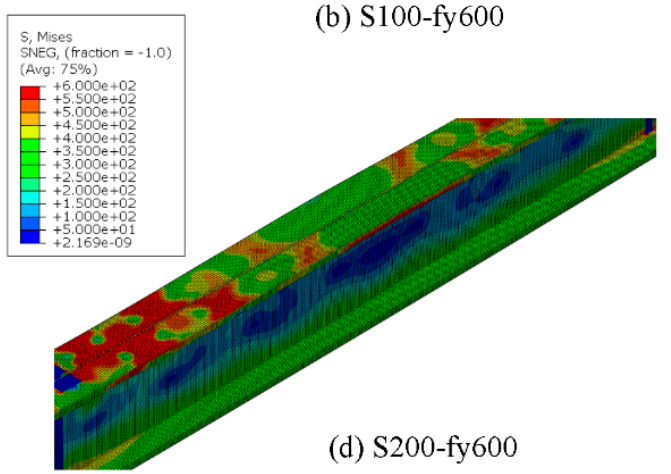

Figure 25. Comparison of bending moment-vertical displacement and failure modes with various screw spacing for open built-up sections.

\subsection{Closed Built-Up Models and Results Analysis}

Closed built-up models were created using unlipped channel sections with intermediate stiffeners that cover an almost similar coil length of open sections. Screw spacings of $100 \mathrm{~mm}$ and $600 \mathrm{~mm}$ were chosen in this study to investigate the flexural behaviour of closed built-up sections. Moreover, two different sets of screw arrangements were used in this study. That is to say, a screw at the middle flange and two screws $15 \mathrm{~mm}$ from both ends of the flanges were used (Figure 21d,e). A moment-displacement curve and failure modes at different stages were observed for single sections as well as for closed built-up sections, and local buckling failure was noticed, followed by failure at the web at the post-failure stage. The bending moment vs. vertical displacement curve and failure modes at various stages for single sections with $600 \mathrm{MPa}$, built-up section with single screw at mid flange at a $600-\mathrm{mm}$ spacing (yield strength of $600 \mathrm{MPa}$ ) and double screws at a $600-\mathrm{mm}$ spacing (yield strength of $600 \mathrm{MPa}$ ) are shown in Figures 26-28. 


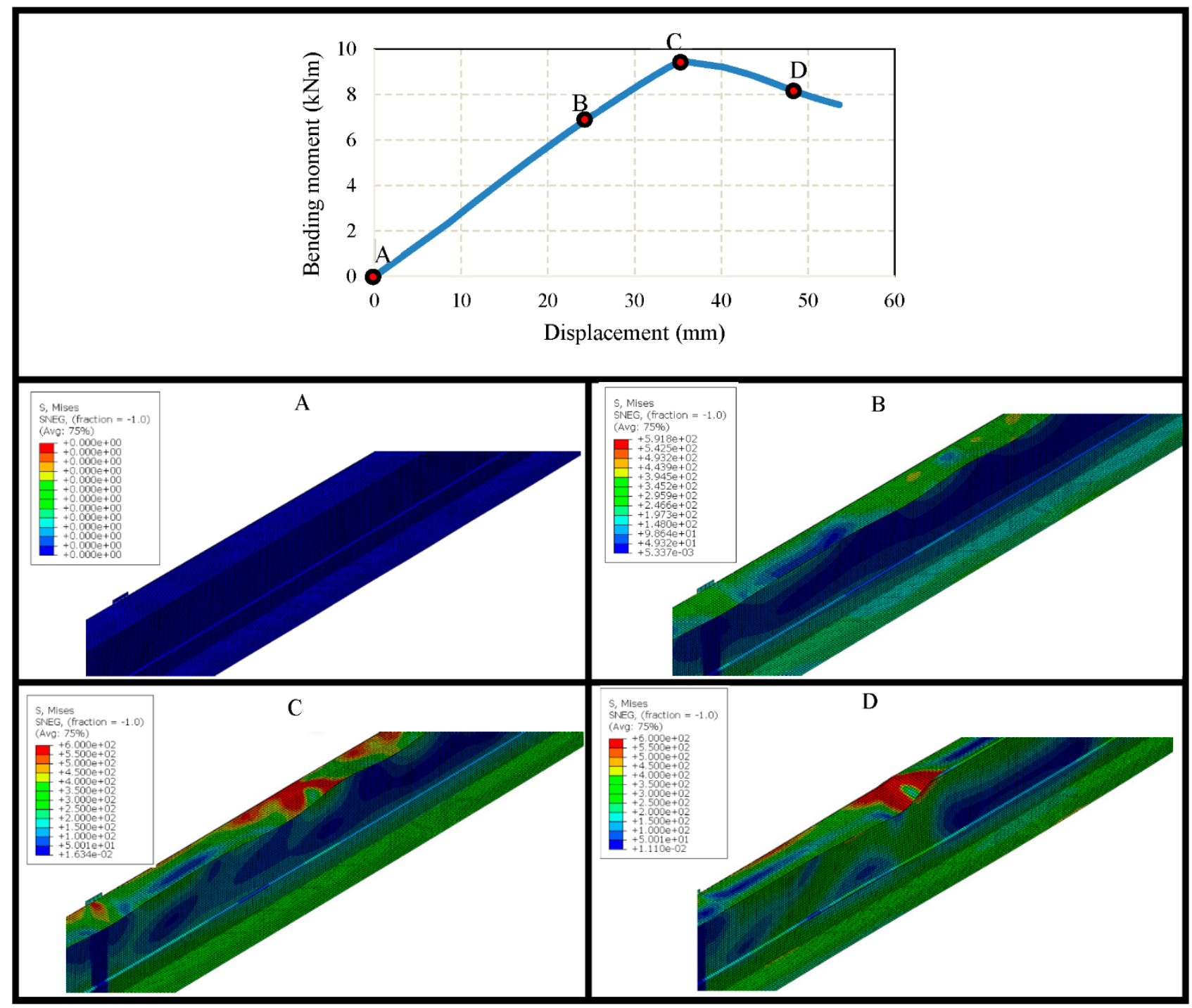

Figure 26. Failure modes and moment-displacement curve of single unlipped channel section $600 \mathrm{MPa}$ of yield strength.

Flexural capacities of closed built-up sections were compared with single sections and capacity enhancement is listed out in Figure 29. A noticeable improvement was observed in closed built-up sections than open sections compared to their single sections. For single screw built-up sections with a yield strength of $450 \mathrm{MPa}, 2.39$ - and 1.97-timesgreater increments were noticed for $100 \mathrm{~mm}$ and $600 \mathrm{~mm}$ spacings, respectively, than that of single section. However, the increment was increased for double screws, and 2.51 and 2.07 was observed for $100 \mathrm{~mm}$ and $600 \mathrm{~mm}$ spacings, respectively. Similarly, the comparison study was performed for sections with a yield strength of $600 \mathrm{MPa}$ and is shown in Figure 29. The bending moment-vertical displacement curve comparison for closed built-up sections with screw spacings of $100 \mathrm{~mm}$ and $600 \mathrm{~mm}$ and respective failure modes are compared in Figures 30 and 31 for single screw and double screws, respectively. 


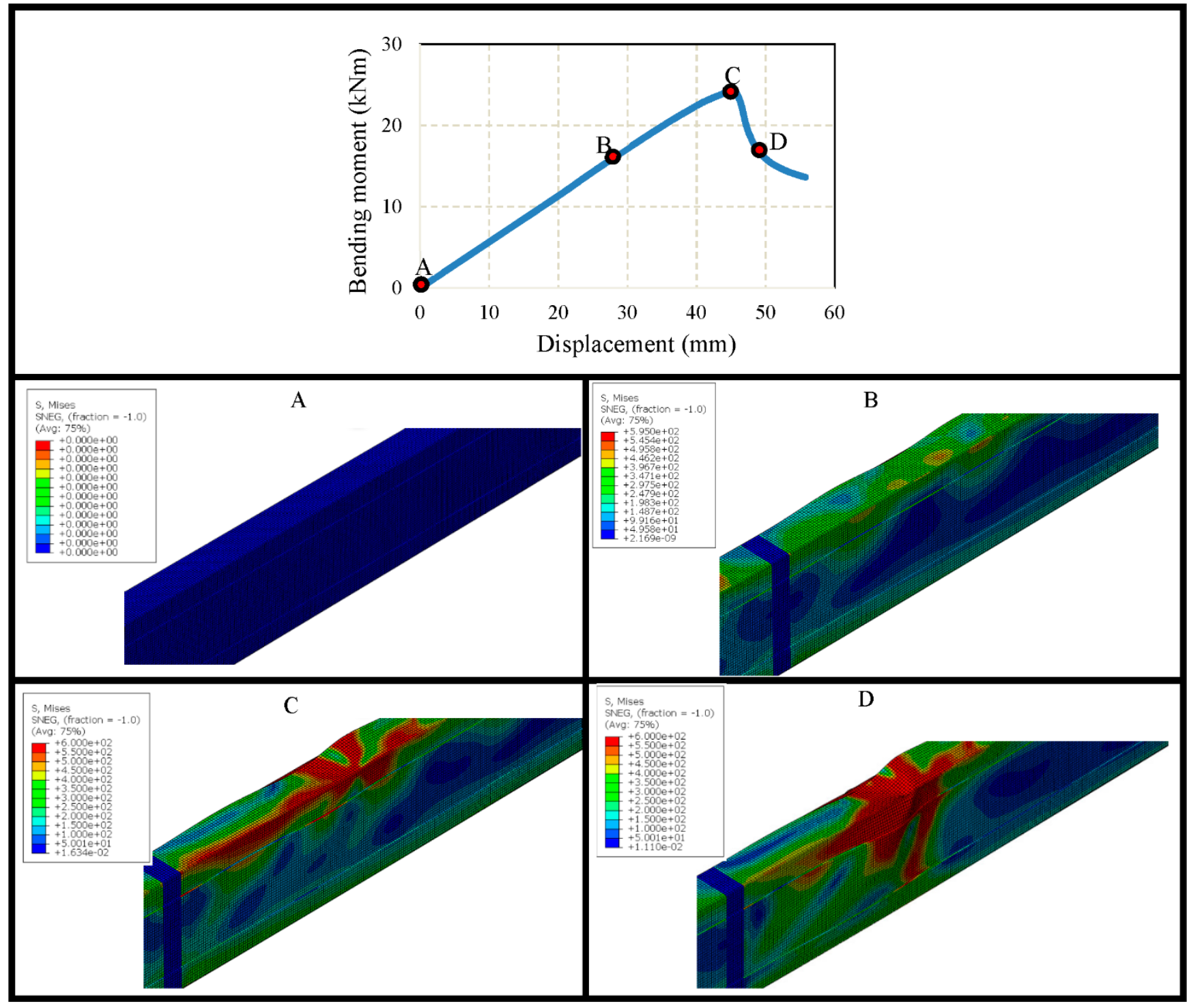

Figure 27. Failure modes and moment-displacement curve of closed built-up model with single screw at $600 \mathrm{~mm}$ spacing and $600 \mathrm{MPa}$ of yield strength. 


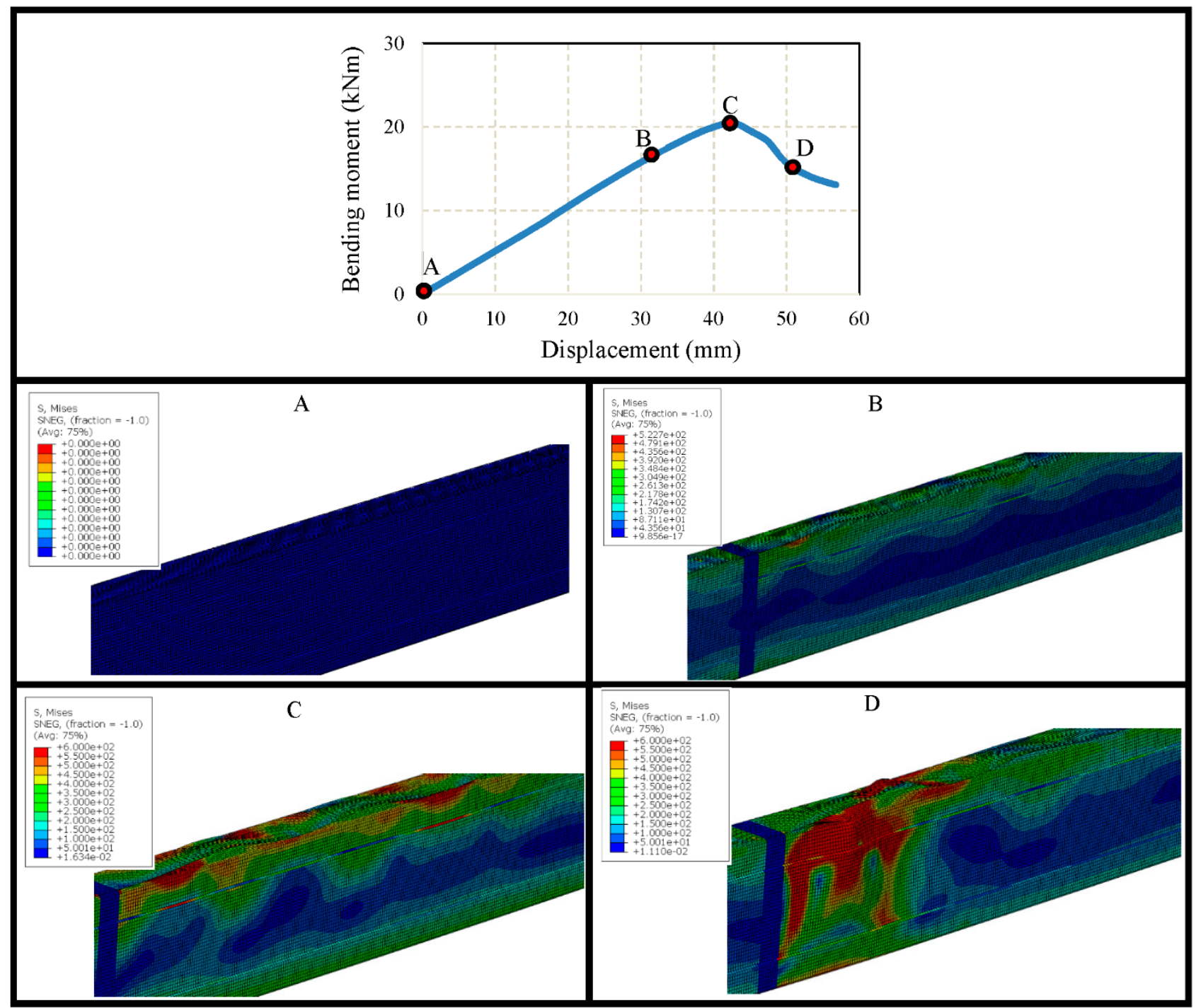

Figure 28. Failure modes and moment-displacement curve of closed built-up model with double screw at $600 \mathrm{~mm}$ spacing and $600 \mathrm{MPa}$ of yield strength.

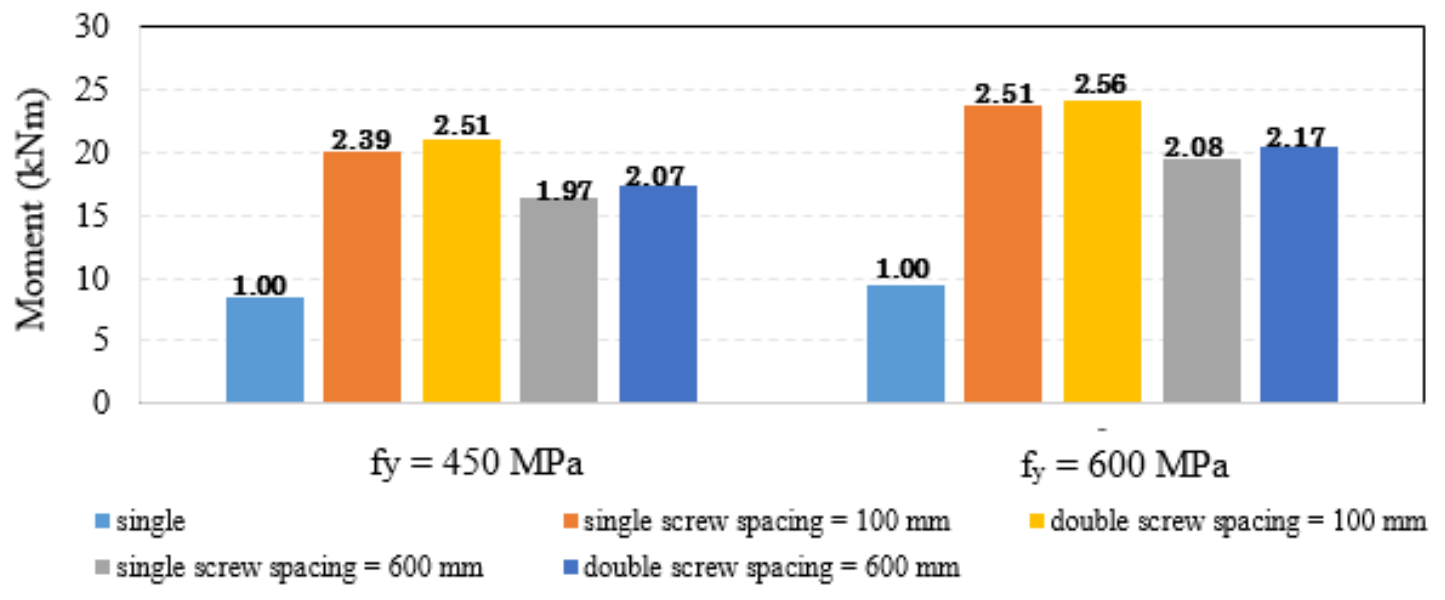

Figure 29. Flexural capacity comparison for closed built-up sections. 

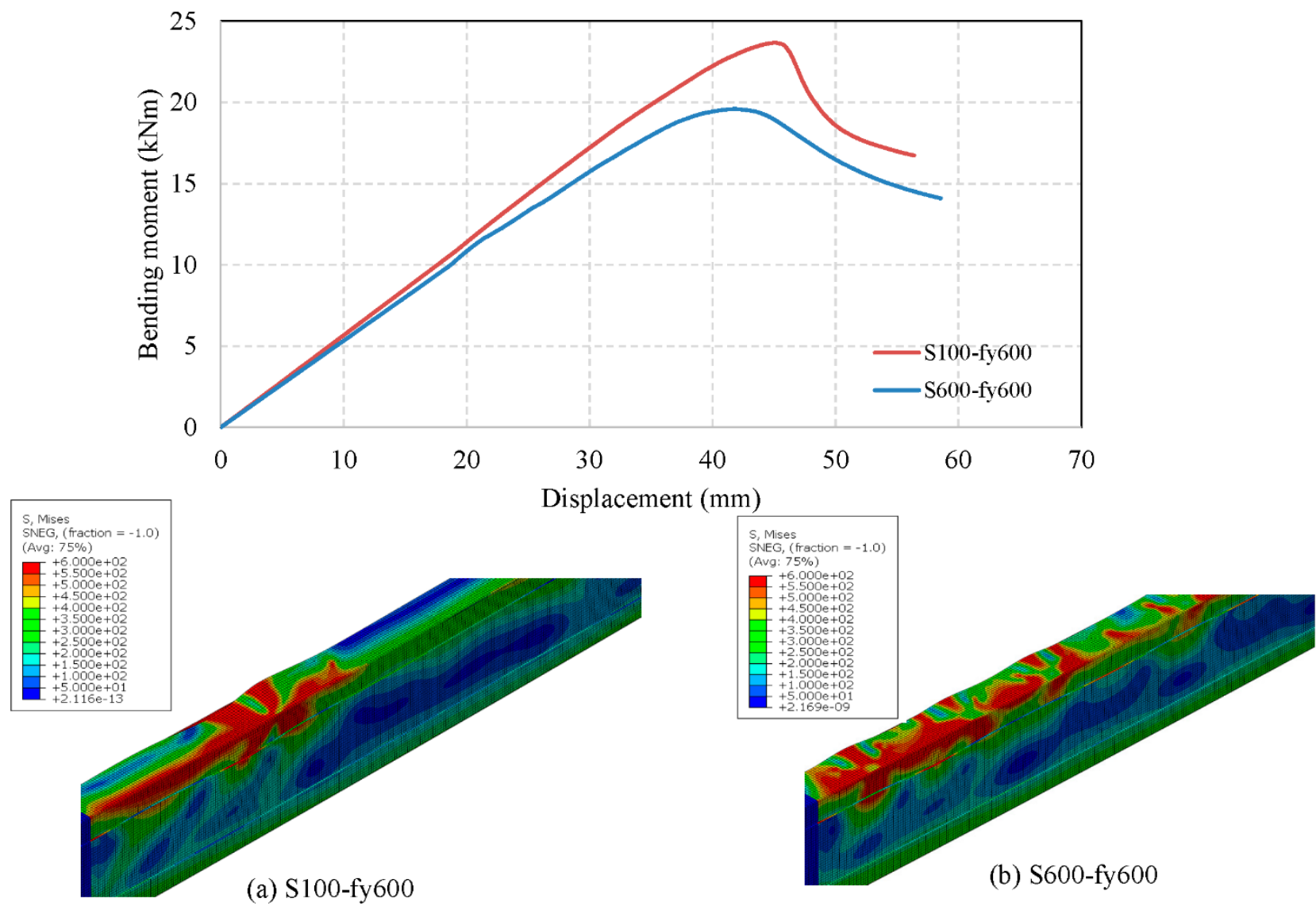

Figure 30. Comparison of bending moment-vertical displacement and failure modes with various screw spacing for closed built-up sections with single screws.

As closed built-up sections enhance the flexural capacity more than open sections, the closed sections can be used in modular construction to enhance the flexural behaviour of joists. In addition, closed built-up sections contain a hollow area that can be filled with various materials, such as wood, for further improvement in flexural capacity. Otherwise, the hollow area could be used to safely accommodate the modular building service conduits. However, further studies and investigation on the improvement of built-up section is required. 


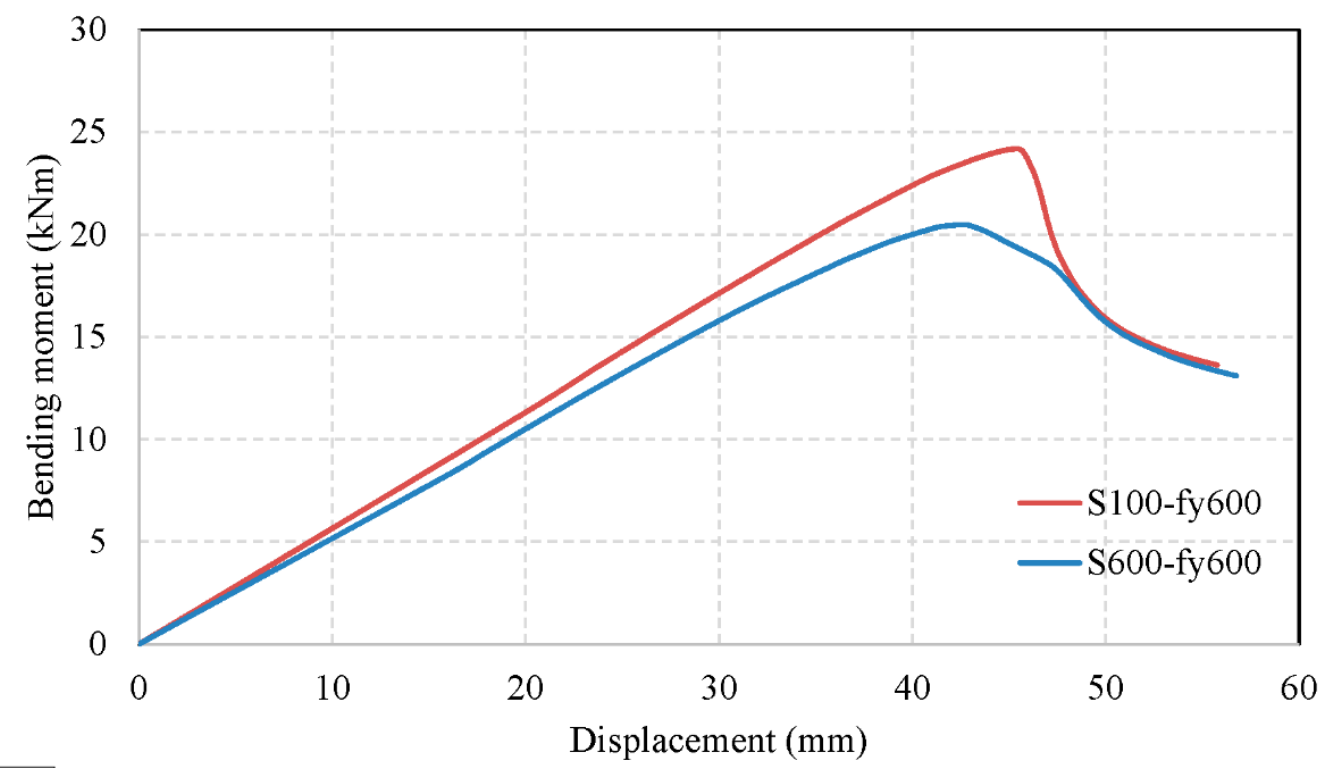

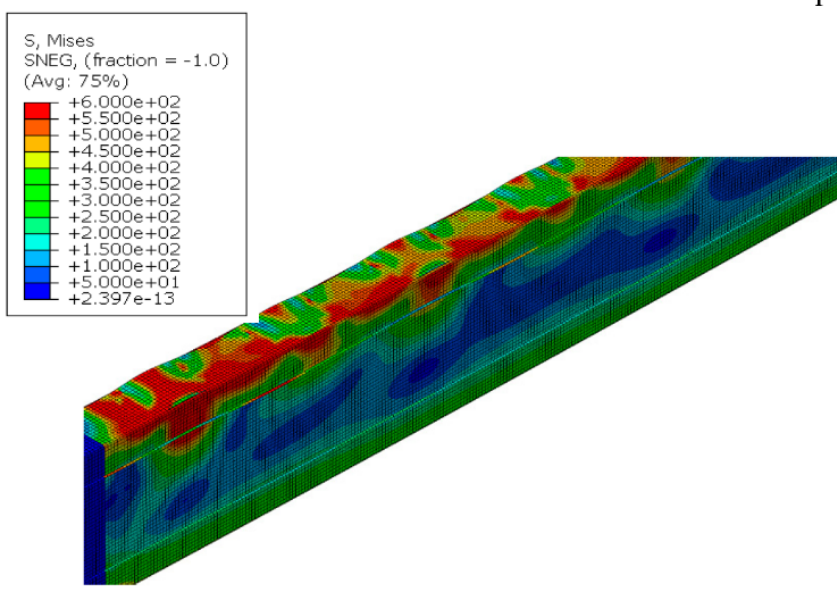

(a) S100-fy600

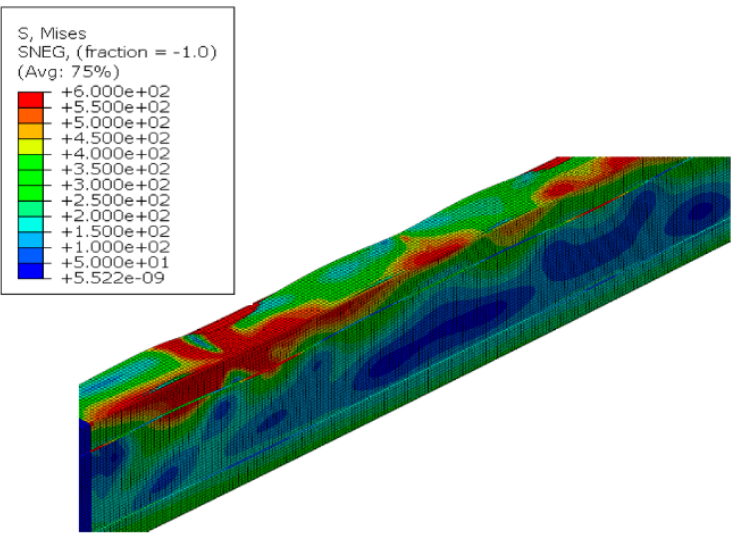

(b) S600-fy600

Figure 31. Comparison of bending moment-vertical displacement and failure modes with various screw spacings for closed built-up sections with double screws.

\section{Conceptual Design of Modular Unit with Enhanced Sustainability Performance}

Various cold-formed steel sections, such as box section, C-section and sigma sections, are already available in the construction industry. Figure 32 illustrates a corner-supported modular building system with conventional beam profiles and proposed innovative builtup sections. The corner supported module is denoted (Figure 32a) with all the elements. Figure 32c shows some innovative built-up sections that can be used in the future with proper codified equations.

According to this study, open built-up sections using lipped channel sections and closed built-up sections using channel sections with intermediate stiffeners enhanced the flexural performance more than that of single sections. Since built-up sections enhance the flexural capacity, they will reduce the required material and minimise the weightage of the construction building. Secondly, the built-up sections are torsionally stable and have a load-bearing capacity; thus, minimal lateral restraints are required to restrain the joist. Thirdly, as the second moment areas of these built-up sections are much greater than traditional sections, they can be used for long spans. Therefore, the required number of intermediate columns will be reduced. Reducing the number of columns would increase the space in the constructions and enhance the indoor atmosphere condition. Therefore, using these built-up sections into the modular construction will positively impact in terms 
of sustainability performances and structural performances, as well as encourage the usage of lightweight materials.

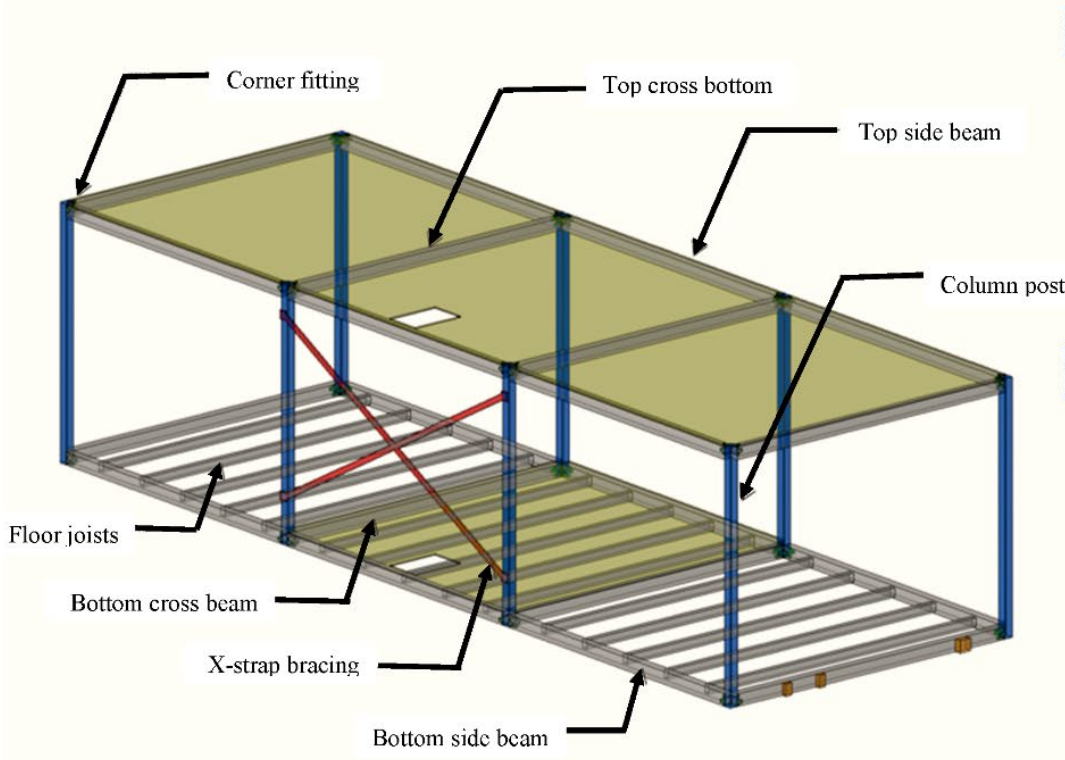

(a) Corner supported modular building system

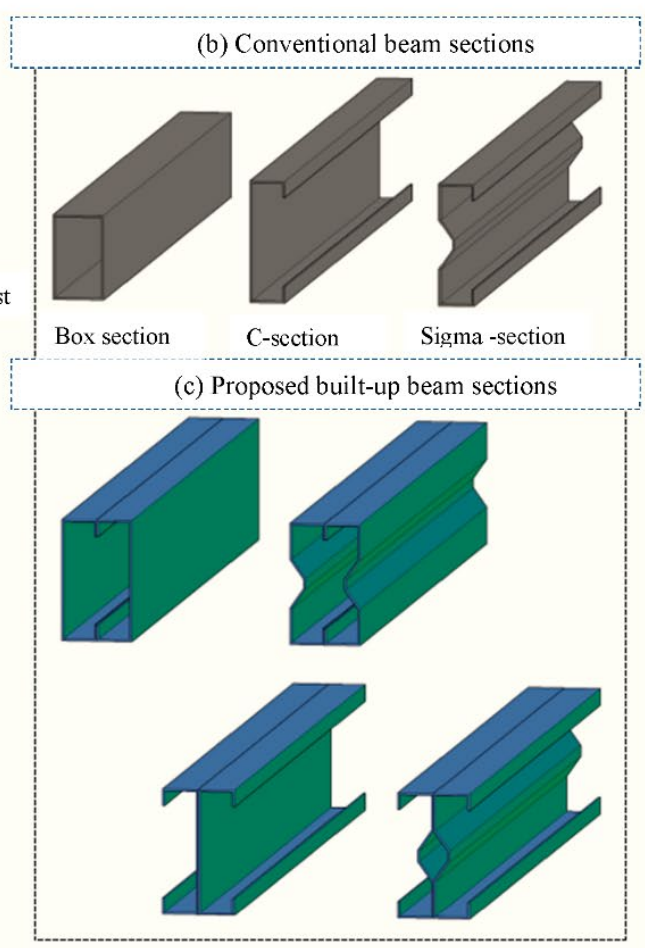

Figure 32. Typical (a) corner-supported steel modular building system with (b) conventional beam sections and (c) proposed cold-formed steel built-up sections.

\section{Recommendations for Future Works}

Built-up sections could play a huge part in MBS applications in future due to their improved flexural performance. Increased span length is another significant reason for using built-up sections in MBS. Hence, further detailed study on the structural behaviour of built-up sections is needed to enhance the utilization of built-up sections in different circumstances. Moreover, research studies on closed built-up sections are in progress, introducing various ideas of filling hollow spaces using various materials (lightweight concrete and timber). On the other hand, the hollow area could be effectively utilized to accommodate the service conduits in modular building. Moreover, innovative sections could be proposed for bearers as well to improve the sustainability performances of modular constructions, and further research on the improvement of built-up section are needed.

\section{Conclusions}

Modular construction is one of the emerging modern methods of construction. However, improved structural performance and material efficiency are the key targets of modular construction which are yet to be achieved to attain the sustainability targets. Built-up sections were introduced to increase the spanning length of the sections, which is commercial to reduce the material utilization. So, built-up sections can be a suitable option for modular construction considering material efficiency. However, the structural performance of built-up sections has to be analysed to investigate the possibilities of application in the modular construction to improve the sustainability aspects of the MBS. This research intended to study the sustainable performance of built-up sections in terms of modular construction needs such as improved flexural performance, sustainability performances and effective material usage. Open built-up sections and closed built-up sections with novel sections were validated and parametric studies were carried out to analyse the 
flexural performance. Different screw spacing and arrangements were considered to study the influence of screw arrangements and screw spacing. Later, results were obtained and compared with selected different parameters. The following notable outcomes as well as predictions were obtained from the analysis.

1. Improved flexural capacity was observed for high yield strength (600 MPa) compared to lower (450 MPa) for open built-up sections. However, screw spacing did not influence the flexural capacity enhancement of open built-up sections much.

2. Well-enhanced bending capacity was observed for high yield strength (600 MPa) compared to lower $(450 \mathrm{MPa})$ for closed built-up sections. Moreover, screw spacing influenced the flexural capacity in both criteria. A double screw spacing of $100 \mathrm{~mm}$ was the optimum spacing, which produced maximum bending capacity in both scenarios. A single screw spacing of $100 \mathrm{~mm}$ was next with better flexural capacity enhancement in both yield strengths. However, for $450 \mathrm{MPa}$, bending capacity enhancement was relatively lower compared to $600 \mathrm{MPa}$ sections and relatively higher compared to any open built-up sections.

3. Bending capacity increases up to $156 \%$ compared to single section. Therefore, the section is a possible option for modular buildings as it satisfies requirements of a modular section.

4. As novel closed sections showcase greater structural performance than open built-up sections when compared to their single sections, closed built-up sections could be considered for future investigations for further improvement of structural performances. The structural performances of novel closed built-up sections could be investigated by filling with various lightweight materials including timber and by optimising the cross sections.

5. Selected feasible sections in modular construction will improve the sustainable performance of the MBS as it reduces the material utilization by eliminating the need of additional studs, as well as it showcases enhanced flexural performance that could ultimately improve the performance of the MBS.

6. Increase in spanning by using built-up sections will enrich the space utilization in a module, which would magnify the indoor atmosphere conditions.

Hence, the idea of utilizing novel built-up sections in MBS will address the modular construction needs in terms of sustainable performance (environmentally effective material utilization, economically cost saving by reducing studs and connections, socially improved indoor environment) as well as structural performance (enhanced flexural capacity). However, further detailed studies on the structural behaviour of novel built-up sections with innovative ideas are in progress for the improvement of sustainability aspects of modular construction.

Author Contributions: Conceptualization, K.P. and P.G.; methodology, K.T. and E.K.; software, K.T.; formal analysis, K.T. and E.K.; data curation, E.K.; writing-original draft preparation, E.K., K.T., H.R. and M.D.; writing-review and editing, K.P., P.G. and T.S.; visualization, P.G.; supervision, K.P. All authors have read and agreed to the published version of the manuscript.

Funding: This research received no external funding.

Institutional Review Board Statement: Not applicable.

Informed Consent Statement: Not applicable.

Data Availability Statement: All the data are displayed in the manuscript.

Acknowledgments: The study was conducted with the support provided by the Northumbria University, The Home Engineers and European research council.

Conflicts of Interest: The authors declare no conflict of interest. 


\section{References}

1. Iuorio, O.; Fiorino, L. Scholars' Mine Sustainability of Modular Lightweight Steel Building from Design to Construction; Missouri University of Science and Technology: Rolla, MO, USA, 2018.

2. Gatheeshgar, P.; Poologanathan, K.; Gunalan, S. Development of affordable steel-framed modular buildings for emergency situations (COVID-19). Structures 2021, 31, 862-875. [CrossRef]

3. Thai, H.T.; Ngo, T.; Uy, B. A review on modular construction for high-rise buildings. Structures 2020, 28, 1265-1290. [CrossRef]

4. Bertram, N.; Fuchs, S.; Mischke, J.; Palter, R.; Strube, G.; Woetzel, J. Modular Construction: From Projects to Products; Capital Projects \& Infrastructure; Mckinsey: Washington, DC, USA, 2019; pp. 1-30.

5. Mcintosh, A.; Craig, H.; Keerthan, P.; Perampalam, G.; Eleni, I.; Heshachanaa, R. Case Studies in Construction Materials Review of the UK' s Off-site Construction Industry. Case Stud. Constr. Mater.. Under Submission.

6. How Can Modular Construction Address Issues in the UK? Available online: https://www.pbctoday.co.uk/news/mmc-news/ modular-construction-uk/92036/ (accessed on 29 March 2021).

7. Young, B.E.; Seidu, R.D.; Thayaparan, M.; Appiah-Kubi, J. Modular Construction Innovation in the UK: The Case of Residential Buildings. In Proceedings of the International Conference on Industrial Engineering and Operations Management, Dubai, United Arab Emirates, 10-12 March 2020; pp. 806-816.

8. Lovell, H. Modern Methods of Construction; NHBC Foundation: Knowlhill, UK, 2012.

9. Murray, P. Factory Made Housing: A Solution for London? New London Architecture: London, UK, 2018.

10. Nazir, F.A.; Edwards, D.J.; Shelbourn, M.; Martek, I. Comparison of modular and traditional UK housing construction: A bibliometric analysis. J. Eng. Des. Technol. 2020, 19, 1-23.

11. Lawson, R.M.; Asce, M.; Ogden, R.G.; Bergin, R. Application of Modular Construction in High-Rise Buildings. J. Archit. Eng. 2012, 18, 148-154. [CrossRef]

12. Waste \& Ressources Action Programme (WRAP). Waste Reduction Potential of Offsite Volumetric Construction. Waste Ressour. Action Programm. 2004, 3, 3-6.

13. Lawson, R.M.; Ogden, R.G. Sustainability and Process Benefits of Modular Construction. In Proceedings of the 18th CIB World Building Congress, Salford, UK, 10-13 May 2010; pp. 38-51.

14. L\&G modular homes losses exceed $£ 100 \mathrm{~m}$. Construction Enquirer News. Available online: https://www.constructionenquirer. com/2020/11/30/lg-modular-homes-losses-exceed-100m/ (accessed on 28 February 2021).

15. NHBC Foundation. Modern Methods of Construction: Views from the Industry; NHBC Foundation: Knowlhill, UK, 2016.

16. NHBC Foundation. Modern Methods of Construction: Building on Experience; NHBC Foundation: Knowlhill, UK, 2021.

17. Lawson, R.M. Building design using modules. Steel Constr. Inst. 2007, 15, 1-16.

18. Royal Institute of Chartered Surveyors (RICS). Modern Methods of Construction Modern Methods of Construction; RICS: London, UK, 2018.

19. Jiang, Y.; Zhao, D.; Wang, D.; Xing, Y. Sustainable Performance of Buildings through Modular Prefabrication in the Construction Phase: A Comparative Study. Sustainability 2019, 11, 5658. [CrossRef]

20. Piroozfar, P.; Larsen, O.P. Handbook Of Research in Mass Customization and Personalization; World Scientific: Singapore, 2010.

21. Modular Vs. Traditional Construction. Available online: https://www.designingbuildings.co.uk/wiki/Modular_vs_traditional_ construction (accessed on 31 March 2021).

22. Farmer, M. The Farmer Review of the UK Construction Labour Model. Des. Build. Wiki 2016, 76. Available online: https: / / www.designingbuildings.co.uk/wiki/Farmer_Review_2016:_Modernise_or_die (accessed on 31 March 2021).

23. Andrew, D. Government-Response-to-the-Farmer-Review. 19 July 2017. Available online: https:/ / www.constructionleadershipcouncil. co.uk/news/government-response-to-the-farmer-review/ (accessed on 31 March 2021).

24. Janton, I. Construction 2019. Ekscentar 2020, 18, 114-115.

25. GOV.UK. Government Construction Strategy GCS 2016-2020. March 2016. Available online: https:/ / www.designingbuildings. co.uk/wiki/Government_Construction_Strategy_2016_2020 (accessed on 30 April 2021).

26. IPA. Proposal for a New Approach to Building: Call for Evidence (Summary of Responses). December 2020. Available online: https:/ / www.gov.uk/government/consultations/proposal-for-a-new-approach-to-building-call-for-evidence (accessed on 30 April 2021).

27. ICI. ICI Strategy 2021-2026; ICI: London, UK, 2021.

28. UNSD. Global Indicator Framework for the Sustainable Development Goals and Targets of the 2030 Agenda for Sustainable Development; UNSD: New York, NY, USA, 2020; pp. 1-21.

29. Buildoffsite. Accelerating the Evolution of Design Management in Construction The COVID-19 Effect; Buildoffsite: London, UK, 2020.

30. Buildoffsite. Buildoffsite Offsite Sector Response to COVID-19 Impact; Buildoffsite: London, UK, 2020; p. 30.

31. Hyams, A.; Mccann, E.; Ferguson, H. Construction Methods: Modular. Building Magazine. 2018, pp. 46-50. Available online: https: / /www.buildoffsite.com/content/uploads/2018/07/Unlocking-the-Potential-of-Modular-Construction_BuildingFINAL-by-Ailea.pdf (accessed on 20 March 2021).

32. The American Institute of Architects. Design for Modular Construction: An Introduction for Architects; National Institute of Building Science: Washington, DC, USA, 2019; pp. 1-41.

33. Lawson, R. Sustainability of Steel in Housing and Residential Buildings; Steel Construction Institute: Ascot, UK, 2007 ; p. 24. 
34. Aye, L.; Gunawardena, T.; Mendis, P.; Ngo, T.; Aye, L.; Alfano, J. Sustainable Prefabricated Modular Buildings. In Proceedings of the 5th International Conference on Sustainable Built Environment, ICSB, Kandy, Sri Lanka, 12-15 December 2014.

35. Gatheeshgar, P.; Poologanathan, K.; Gunalan, S. Optimal design of cold-formed steel lipped channel beams: Combined bending, shear, and web crippling. Structures 2020, 28, 825-836. [CrossRef]

36. Janarthanan, B.; Elilarasi, K.; Selvarajasarma, K. Effect of Circular Openings on Web Crippling of Unlipped Channel Sections Under End-Two-Flange Load Case. Adv. Steel Constr. 2020, 16, 310-320.

37. Elilarasi, K.; Janarthanan, B. Effect of web holes on the web crippling capacity of cold-formed LiteSteel beams under End-TwoFlange load case. Structures 2019, 25, 411-425. [CrossRef]

38. Keerthan, P.; Mahendran, M. New design rules for the shear strength of LiteSteel beams. J. Constr. Steel Res. 2011, 67, 1050-1063. [CrossRef]

39. Keerthan, P.; Mahendran, M. Experimental studies on the shear behaviour and strength of LiteSteel beams. Eng. Struct. 2010, 32, 3235-3247. [CrossRef]

40. Keerthan, P.; Mahendran, M. Elastic shear buckling characteristics of LiteSteel beams. J. Constr. Steel Res. 2010, 66, 1309-1319. [CrossRef]

41. Keerthan, P.; Mahendran, M.; Steau, E. Experimental study of web crippling behaviour of hollow flange channel beams under two flange load cases. Thin-Walled Struct. 2014, 85, 207-219. [CrossRef]

42. Keerthan, P.; Mahendran, M.; Hughes, D. Numerical studies and design of hollow flange channel beams subject to combined bending and shear actions. Eng. Struct. 2014, 75, 197-212. [CrossRef]

43. Keerthan, P.; Mahendran, M. Improved shear design rules for lipped channel beams with web openings. J. Constr. Steel Res. 2014, 97, 127-142. [CrossRef]

44. Keerthan, P.; Mahendran, M. Experimental studies of the shear behaviour and strength of lipped channel beams with web openings. Thin-Walled Struct. 2013, 73, 131-144. [CrossRef]

45. Navaratnam, S.; Widdowfield, D.; Gatheeshgar, P.; Poologanathan, K.; Thamboo, J.; Higgins, C.; Mendis, P. Development of cross laminated timber-cold-formed steel composite beam for floor system to sustainable modular building construction. Structures 2021, 32, 681-690. [CrossRef]

46. Gatheeshgar, P.; Poologanathan, K.; Gunalan, S. Optimised cold-formed steel beams in modular building applications. J. Build. Eng. 2020, 32, 101607. [CrossRef]

47. Wang, L.; Young, B. Behaviour and design of cold-formed steel built-up section beams with different screw arrangements. Thin Walled Struct. 2018, 131, 16-32. [CrossRef]

48. Li, Y.L.; Li, Y.Q.; Shen, Z.Y. Investigation on flexural strength of cold-formed thin-walled steel beams with built-up box section. Thin-Walled Struct. 2016, 107, 66-79. [CrossRef]

49. Diplock, T.; Wheatland, J.; Singh, H. Back to Basics: Why the U.K. Construction Sector Must Focus on Fundamentals. Exec. Insights 2019, 21, 1-5.

50. Park, H.K.; Ock, J.H. Unit modular in-fill construction method for high-rise buildings. KSCE J. Civ. Eng. 2016, 20, 1201-1210. [CrossRef]

51. Kamali, M.; Hewage, K. Development of performance criteria for sustainability evaluation of modular versus conventional construction methods. J. Clean. Prod. 2017, 142, 3592-3606. [CrossRef]

52. Rajanayagam, H.; Poologanathan, K.; Gatheeshgar, P.; Varelis, G.E.; Sherlock, P.; Nagaratnam, B.; Hackney, P. A-State-Of-The-Art review on modular building connections. Structures 2021, 34, 1903-1922. [CrossRef]

53. Lacey, A.W.; Chen, W.; Hao, H.; Bi, K. Structural response of modular buildings-An overview. J. Build. Eng. 2018, 16, 45-56. [CrossRef]

54. Dhanapal, J.; Ghaednia, H.; Das, S.; Velocci, J. Structural performance of state-of-the-art VectorBloc modular connector under axial loads. Eng. Struct. 2019, 183, 496-509. [CrossRef]

55. Bowron, J.; Gulliford, J.; Churchill, E.; Cerone, J.; Mallie, J. United States Patent. U.S. Patent 9.458,619 B2, 4 October 2016. Available online: https:/ / patentimages.storage.googleapis.com/7e/6d/cc/0b8820f9074747/US9458619.pdf (accessed on 30 April 2021).

56. Gunawardena, T. Behaviour of Prefabricated Modular Buildings Subjected to Lateral Loads. 2016. Available online: https:// www.researchgate.net/publication/322040294_Behaviour_of_Prefabricated_Modular_Buildings_Subjected_to_Lateral_Loads (accessed on 30 April 2021).

57. Doh, J.H.; Ho, N.M.; Miller, D.; Peters, T.; Carlson, D.; Lai, P. Steel Bracket Connection on Modular Buildings. J. Steel Struct. Constr. 2017, 2. [CrossRef]

58. Grenfell Tower: What Happened. BBC News. Available online: https://www.bbc.com/news/uk-40301289 (accessed on 30 April 2021).

59. Polley, S. Approved Document B: Fire safety. Underst. Build. Regul. 2020, 6, $42-97$.

60. Lawson, R.M.; Way, A.G.J. Fire Safety of Light Steel Construction. Steel Constr. Inst. 2012, 1-4. Available online: https: / / steel-sci.com/assets/downloads/LSF/ED016\%20Download.pdf (accessed on 30 April 2021).

61. Gatheeshgar, P.; Poologanathan, K.; Thamboo, J.; Roy, K.; Rossi, B.; Molkens, T.; Perera, D.; Navaratnam, S. On the fire behaviour of modular floors designed with optimised cold-formed steel joists. Structures 2021, 30, 1071-1085. [CrossRef]

62. Nguyen, K.T.Q.; Navaratnam, S.; Mendis, P.; Zhang, K.; Barnett, J.; Wang, H. Fire safety of composites in prefabricated buildings: From fibre reinforced polymer to textile reinforced concrete. Compos. Part B Eng. 2020, 187, 107815. [CrossRef] 
63. Mohammad, M.; Masad, E.; Al-Ghamdi, S.G. 3D Concrete Printing Sustainability: A Comparative Life Cycle Assessment of Four Construction Method Scenarios. Buildings 2020, 10, 245. [CrossRef]

64. Blismas, N.; Pasquire, C.; Gibb, A. Benefit evaluation for off-site production in construction. Constr. Manag. Econ. 2006, 24, 121-130. [CrossRef]

65. Boafo, F.E.; Kim, J.H.; Kim, J.T. Performance of modular prefabricated architecture: Case study-based review and future pathways. Sustainability 2016, 8, 558. [CrossRef]

66. Cao, X.; Li, X.; Zhu, Y.; Zhang, Z. A comparative study of environmental performance between prefabricated and traditional residential buildings in China. J. Clean. Prod. 2015, 109, 131-143. [CrossRef]

67. Horta, I.M.; Camanho, A.S.; Johnes, J.; Johnes, G. Performance trends in the construction industry worldwide: An overview of the turn of the century. J. Product. Anal. 2013, 39, 89-99. [CrossRef]

68. Crosthwaite, D. The global construction market: A cross-sectional analysis. Constr. Manag. Econ. 2000, 18, 619-627. [CrossRef]

69. Hossain, M.A.; Zhumabekova, A.; Paul, S.C.; Kim, J.R. A review of 3D printing in construction and its impact on the labor market. Sustainability 2020, 12, 8492. [CrossRef]

70. Minunno, R.; O'Grady, T.; Morrison, G.M.; Gruner, R.L.; Colling, M. Strategies for applying the circular economy to prefabricated buildings. Buildings 2018, 8, 125. [CrossRef]

71. Lawson, R.M. Sustainability of Light Steel Construction. SCI Steel 2010, 1-4. Available online: https://steel-sci.com/assets / downloads/LSF/ED020\%20Download.pdf (accessed on 30 April 2021).

72. Tam, V.W.Y.; Hao, J.J.L. Prefabrication as a mean of minimizing construction waste on site. Int. J. Constr. Manag. 2014, 14, 113-121. [CrossRef]

73. Simulia, D.S. Abaqus CAE User's Manual (6.12); Dassaualt Systems: Washington, DC, USA, 2012; p. 1174.

74. Gatheeshgar, P.; Parker, S.; Askew, K.; Poologanathan, K.; Navaratnam, S.; McIntosh, A.; Small, D.W. Flexural behaviour and design of modular construction optimised beams. Structures 2021, 32, 1048-1068. [CrossRef] 